\title{
The Real Exchange Rate and Economic Growth
}

\begin{abstract}
I show that undervaluation of the currency (a high real exchange rate) stimulates economic growth. This is true particularly for developing countries. This finding is robust to using different measures of the real exchange rate and different estimation techniques. I also provide some evidence that the operative channel is the size of the tradable sector (especially industry). These results suggest that tradables suffer disproportionately from the government or market failures that keep poor countries from converging toward countries with higher incomes. I present two categories of explanations for why this may be so, the first focusing on institutional weaknesses, and the second on product-market failures. A formal model elucidates the linkages between the real exchange rate and the rate of economic growth.
\end{abstract}

- conomists have long known that poorly managed exchange rates can of the currency is one of the most robust imperatives that can be gleaned from the diverse experience with economic growth around the world, and one that appears to be strongly supported by cross-country statistical evidence. ${ }^{1}$ The results reported in the well-known papers by David Dollar and by Jeffrey Sachs and Andrew Warner on the relationship between outward orientation and economic growth are largely based on indices that capture the degree of overvaluation. ${ }^{2}$ Much of the literature that derives policy recommendations from cross-national regressions is now in disrepute, ${ }^{3}$ but it

1. Razin and Collins (1997); Johnson, Ostry, and Subramanian (2007); Rajan and Subramanian (2006).

2. Dollar (1992); Sachs and Warner (1995); Rodriguez and Rodrik (2001).

3. Easterly (2005); Rodrik (2005). 
is probably fair to say that the admonishment against overvaluation remains as strong as ever. In his pessimistic survey of the cross-national growth literature, ${ }^{4}$ William Easterly agrees that large overvaluations have an adverse effect on growth (although he remains skeptical that moderate movements have determinate effects).

Why overvaluation is so consistently associated with slow growth is not always theorized explicitly, but most accounts link it to macroeconomic instability. ${ }^{5}$ Overvalued currencies are associated with foreign currency shortages, rent seeking and corruption, unsustainably large current account deficits, balance of payments crises, and stop-and-go macroeconomic cycles, all of which are damaging to growth.

I will argue that this is not the whole story. Just as overvaluation hurts growth, so undervaluation facilitates it. For most countries, periods of rapid growth are associated with undervaluation. In fact, there is little evidence of nonlinearity in the relationship between a country's real exchange rate and its economic growth: an increase in undervaluation boosts economic growth just as powerfully as a decrease in overvaluation. But this relationship holds only for developing countries; it disappears when the sample is restricted to richer countries, and it gets stronger the poorer the country. These findings suggest that more than macroeconomic stability is at stake. The relative price of tradable goods to nontradable goods (that is, the real exchange rate) seems to play a more fundamental role in the convergence of developing country with developed country incomes. ${ }^{6}$

I attempt to make the point as directly as possible in figure 1 , which depicts the experience of seven developing countries during 1950-2004: China, India, South Korea, Taiwan, Uganda, Tanzania, and Mexico. In each case I have graphed side by side my measure of real undervaluation (defined in the next section) against the country's economic growth rate in the same period. Each point represents an average for a five-year window.

To begin with the most fascinating (and globally significant) case, the degree to which economic growth in China tracks the movements in my index of undervaluation is uncanny. The rapid increase in annual growth of GDP per capita starting in the second half of the 1970s closely parallels the increase in the undervaluation index (from an overvaluation of close to

4. Easterly (2005).

5. See, for example, Fischer (1993).

6. Recently, Bhalla (forthcoming), Gala (2007), and Gluzmann, Levy-Yeyati, and Sturzenegger (2007) have made similar arguments. 
Figure 1. Undervaluation and Economic Growth in Selected Developing Countries, 1950-2004

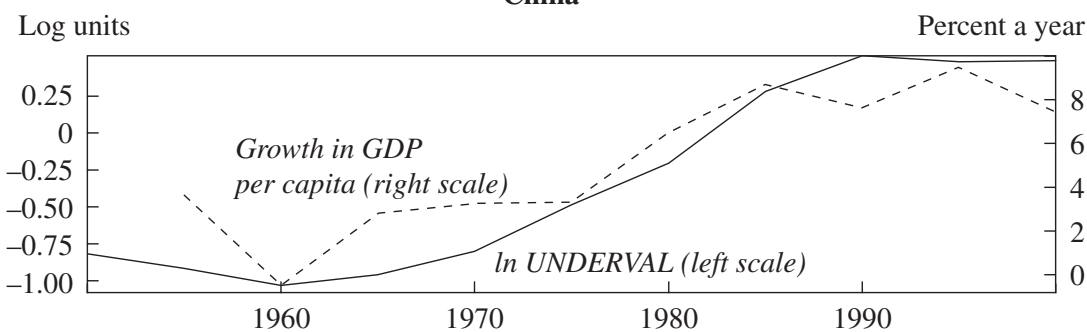

India

Log units

Percent a year

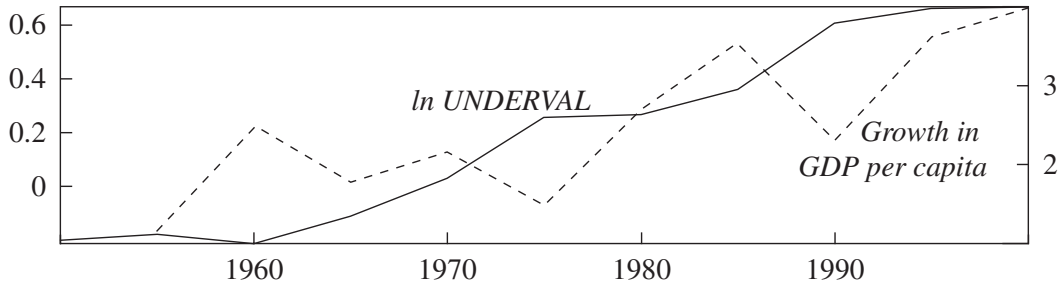

South Korea

Log units

Percent a year

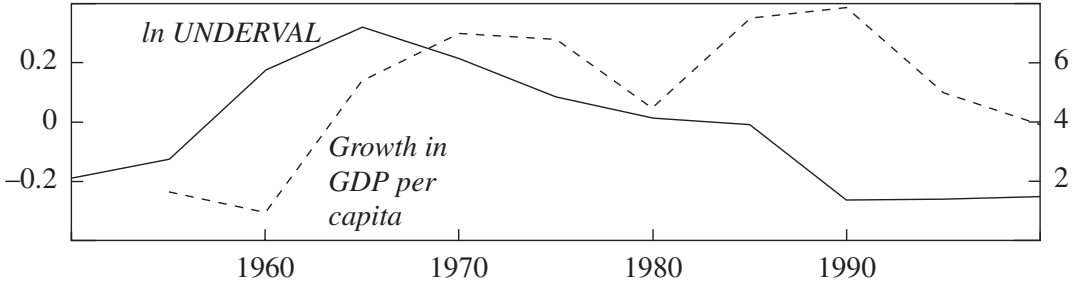

Taiwan

Log units

Percent a year

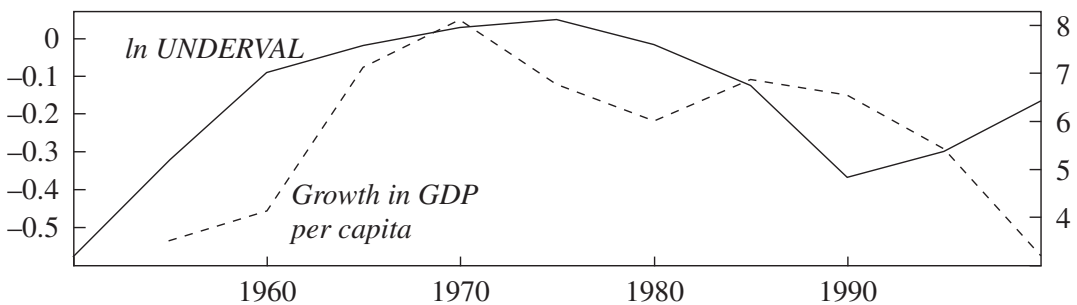

(continued) 
Figure 1. Undervaluation and Economic Growth in Selected Developing Countries, 1950-2004 (Continued)

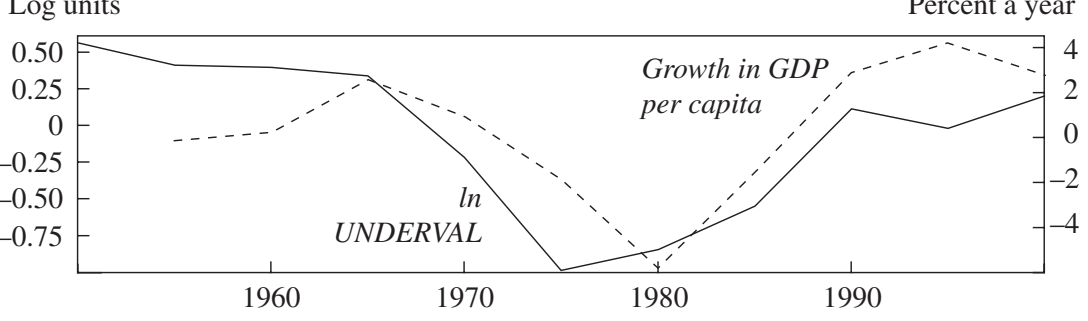

Log units

Tanzania

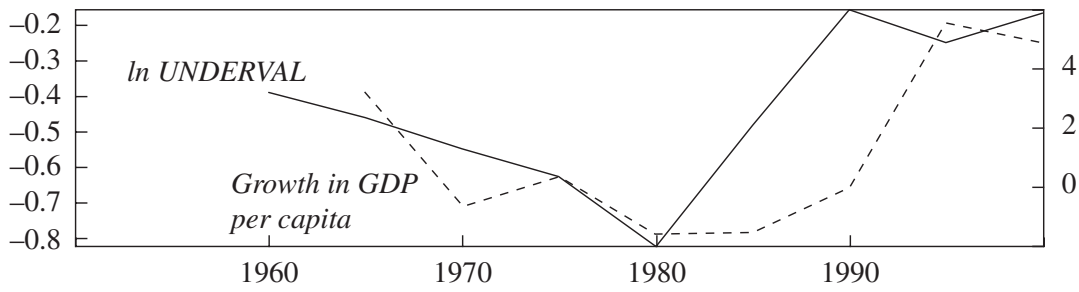

Mexico

Log units

Percent a year

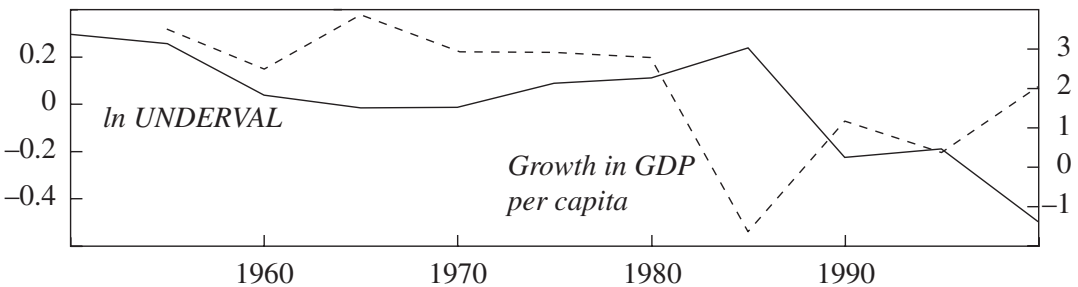

Sources: Penn World Tables version 6.2, and author's calculations.

100 percent to an undervaluation of around 50 percent $^{7}$ ), and both undervaluation and the growth rate plateau in the 1990s. Analysts who focus on global imbalances have, of course, noticed in recent years that the yuan is undervalued, as evidenced by China's large current account surplus. They have paid less attention to the role that undervaluation seems to have played in driving the country's economic growth.

7. Recent revisions in purchasing power parity indices are likely to make a big difference to the levels of these undervaluation measures, without greatly affecting their trends over time. See the discussion below. 
For India, the other growth superstar of recent years, the picture is less clear-cut, but the basic message is the same as that for China. India's growth in GDP per capita has steadily climbed from slightly above 1 percent a year in the 1950s to 4 percent by the early 2000s, while its real exchange rate has moved from a small overvaluation to an undervaluation of around 60 percent. In the case of the two East Asian tigers depicted in figure 1, South Korea and Taiwan, what is interesting is that the growth slowdowns in recent years were in each case preceded or accompanied by increased overvaluation or reduced undervaluation. In other words, both growth and undervaluation exhibit an inverse-U shape over time.

These regularities are hardly specific to Asian countries. The next two panels in figure 1 depict two African experiences, those of Uganda and Tanzania, and here the undervaluation index captures the turning points in economic growth exceptionally well. A slowdown in growth is accompanied by increasing overvaluation, and a pickup in growth is accompanied by a rise in undervaluation. Finally, the last panel of figure 1 shows a somewhat anomalous Latin American case, that of Mexico. Here the two series seem quite a bit out of sync, especially since 1981, when the correlation between growth and undervaluation turns negative rather than positive. Those familiar with the recent economic history of Mexico will recognize this to be a reflection of the cyclical role of capital inflows in inducing growth in that country. Periods of capital inflows in Mexico are associated with consumption-led growth booms and currency appreciation; when the capital flows reverse, the economy tanks and the currency depreciates. The Mexican experience is a useful reminder that there is no reason a priori to expect a positive relationship between growth and undervaluation. It also suggests the need to go beyond individual cases and undertake a more systematic empirical analysis.

In the next section I do just that. First, I construct a time-varying index of real undervaluation, based on data from the Penn World Tables on price levels in individual countries. My index of undervaluation is essentially a real exchange rate adjusted for the Balassa-Samuelson effect: this measure of the real exchange rate adjusts the relative price of tradables to nontradables for the fact that as countries grow rich, the relative prices of nontradables as a group tend to rise (because of higher productivity in tradables). I next show, in regressions using a variety of fixed-effects panel specifications, that there is a systematic positive relationship between growth and undervaluation, especially in developing countries. This indicates that the Asian experience is not an anomaly. I subject these baseline results to a series of robustness tests, employing different data sources, a range of alter- 
native undervaluation indices, and different estimation methods. Although ascertaining causality is always difficult, I argue that in this instance causality is likely to run from undervaluation to growth rather than the other way around. I also present evidence that undervaluation works through its positive impact on the share of tradables in the economy, especially industry. Hence developing countries achieve more rapid growth when they are able to increase the relative profitability of their tradables.

These results suggest strongly that there is something "special" about tradables in countries with low to medium incomes. In the rest of the paper I examine the reasons behind this regularity. What is the precise mechanism through which an increase in the relative price of tradables (and therefore the sector's relative size) increases growth? I present two classes of theories that would account for the stylized facts. In one, tradables are "special" because they suffer disproportionately (that is, compared with nontradables) from the institutional weakness and inability to completely specify contracts that characterize lower-income environments. In the other, tradables are "special" because they suffer disproportionately from the market failures (information and coordination externalities) that block structural transformation and economic diversification. In both cases, an increase in the relative price of tradables acts as a second-best mechanism to partly alleviate the relevant distortion, foster desirable structural change, and spur growth. Although I cannot discriminate sharply between the two theories and come down in favor of one or the other, I present some evidence that suggests that these two sets of distortions do affect tradable activities more than they do nontradables. This is a necessary condition for my explanations to make sense.

In the penultimate section of the paper, I develop a simple growth model to elucidate how the mechanisms I have in mind might work. The model is that of a small, open economy in which the tradable and nontradable sectors both suffer from an economic distortion. For the purposes of the model, whether the distortion is of the institutional and contracting kind or of the conventional market failure kind is of no importance. The crux is the relative magnitude of the distortions in the two sectors. I show that when the distortion in tradables is larger, the tradable sector is too small in equilibrium. A policy or other exogenous shock that can induce a real depreciation will then have a growth-promoting effect. For example, an outward transfer, which would normally reduce domestic welfare, can have the reverse effect because it increases the equilibrium relative price of tradables and can thereby increase economic growth. The model clarifies how changes in relative prices can produce growth effects in the presence of 
distortions that affect the two sectors differently. It also clarifies the sense in which the real exchange rate is a "policy" variable: changing its level requires complementary policies (here the size of the inward or outward transfer).

I summarize my findings and discuss some policy issues in the concluding section of the paper.

\section{Undervaluation and Growth: The Evidence}

I will use a number of different indices in what follows, but my preferred index of under- or overvaluation is a measure of the domestic price level adjusted for the Balassa-Samuelson effect. This index has the advantage that it is comparable across countries as well as over time. I compute this index in three steps. First, I use data on exchange rates (XRAT) and purchasing power parity conversion factors $(P P P)$ from the Penn World Tables version 6.2 to calculate a "real" exchange rate $(R E R):{ }^{8}$

$$
\ln R E R_{i t}=\ln \left(X R A T_{i t} / P P P_{i t}\right),
$$

where $i$ indexes countries and $t$ indexes five-year time periods. (Unless specified otherwise, all observations are simple averages across years.) $X R A T$ and $P P P$ are expressed as national currency units per U.S. dollar. ${ }^{9}$ Values of $R E R$ greater than one indicate that the value of the currency is lower (more depreciated) than indicated by purchasing power parity. However, in practice nontradable goods are also cheaper in poorer countries (through the Balassa-Samuelson effect), which requires an adjustment. So in the second step I account for this effect by regressing $R E R$ on GDP per capita $(R G D P C H)$ :

$$
\ln R E R_{i t}=\alpha+\beta \ln R G D P C H_{i t}+f_{t}+u_{i t},
$$

where $f_{t}$ is a fixed effect for time period and $u$ is the error term. This regression yields an estimate of $\beta$ ( $\hat{\beta}$ ) of -0.24 (with a very high $t$ statistic of around 20), suggesting a strong and precisely estimated Balassa-Samuelson effect: when incomes rise by 10 percent, the real exchange rate falls by around 2.4 percent. Finally, to arrive at my index of undervaluation, I take the difference between the actual real exchange rate and the BalassaSamuelson-adjusted rate:

8. The Penn World Tables data are from Heston, Summers, and Aten (2006).

9. The variable $p$ in the Penn World Tables (called the "price level of GDP") is equivalent to RER. I have used $p$ here as this series is more complete than XRAT and PPP. 


$$
\ln U N D E R V A L_{i t}=\ln R E R_{i t}-\ln \widehat{R E R_{i t}} \text {, }
$$

where $\ln \widehat{R E R}$ is the predicted value from equation 1.

Defined in this way, UNDERVAL is comparable across countries and over time. Whenever UNDERVAL exceeds unity, it indicates that the exchange rate is set such that goods produced at home are relatively cheap in dollar terms: the currency is undervalued. When UNDERVAL is below unity, the currency is overvalued. In what follows I will typically use the logarithmic transform of this variable, ln UNDERVAL, which is centered at zero and has a standard deviation of 0.48 (figure 2). This is also the measure used in figure 1.

My procedure is fairly close to that followed in recent work by Simon Johnson, Jonathan Ostry, and Arvind Subramanian. ${ }^{10}$ The main difference is that these authors estimate a different cross section for equation 1 for each year, whereas I estimate a single panel (with time dummies). My method seems preferable for purposes of comparability over time. I emphasize that my definition of undervaluation is based on price comparisons and differs substantially from an alternative definition that relates to the external balance. The latter is typically operationalized by specifying a small-scale macro model and estimating the level of the real exchange rate that would achieve balance of payments equilibrium. ${ }^{11}$

One issue of great significance for my calculations is that the World Bank's International Comparison Program has recently published revised PPP conversion factors for a single benchmark year, 2005. ${ }^{12}$ In some important instances, these new estimates differ greatly from those previously available and on which I have relied here. For example, price levels in both China and India are now estimated to be around 40 percent above the previous estimates for 2005, indicating that these countries' currencies were not nearly as undervalued in that year as the old numbers suggested (15 to 20 percent as opposed to 50 to 60 percent). This is not as damaging to my results as it may seem at first sight, however. Virtually all my regressions are based on panel data and include a full set of country and time fixed effects. In other words, as I did implicitly in figure 1, I identify the growth effects of undervaluation from changes within countries, not from differences in levels across a cross section of countries. So my results

10. Johnson, Ostry, and Subramanian (2007).

11. See Aguirre and Calderón (2005), Razin and Collins (1997), and Elbadawi (1994) for some illustrations.

12. International Comparison Program (2007). 
Figure 2. Distribution of the Undervaluation Measure

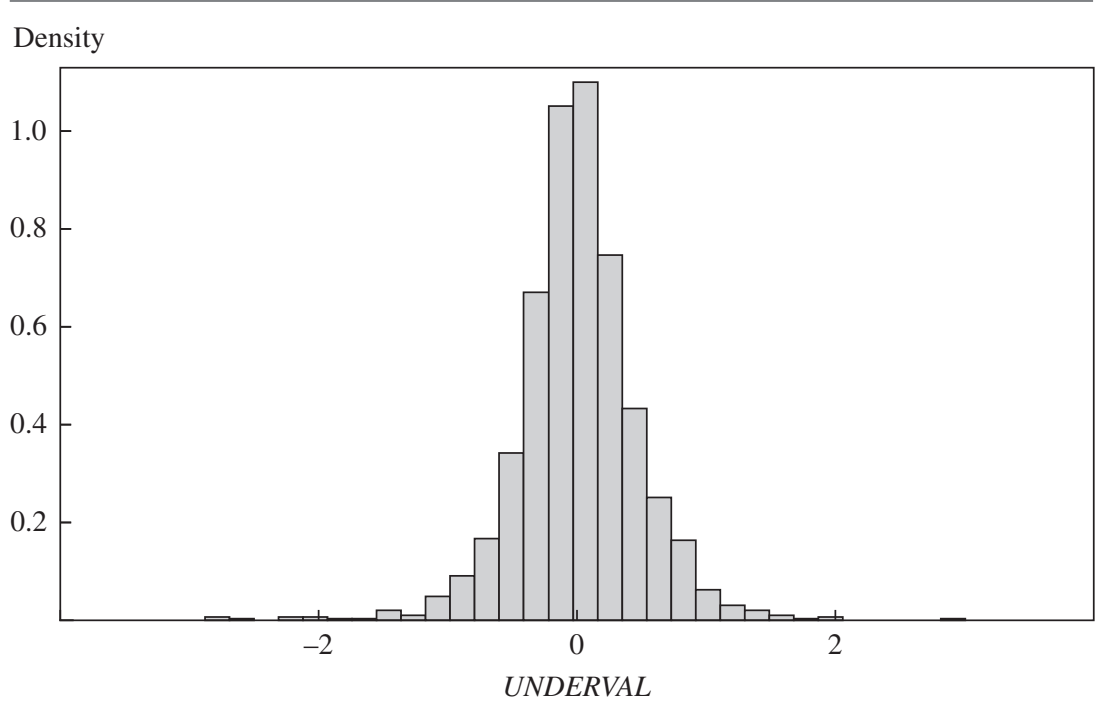

Source: Author's calculations.

should remain unaffected if the revisions to the PPP factors turn out to consist of largely one-time adjustments to the estimated price levels of individual countries, without greatly altering their time trends. Even though the time series of revised PPP estimates are not yet available, preliminary indications suggest that this will be the case.

In fact, the revised data yield a cross-sectional estimate of $\beta$ for 2005 that is virtually the same as the one presented above $(-0.22$, with a $t$ statistic of 11). In other words, the magnitude of the Balassa-Samuelson effect is nearly identical whether estimated with the new data or the old.

\section{The Baseline Panel Evidence}

My dataset covers a maximum of 188 countries and 11 five-year periods from 1950-54 through 2000-04. My baseline specification for estimating the relationship between undervaluation and growth takes the following form:

(2) growth $_{i t}=\alpha+\beta \ln R G D P C H_{i, t-1}+\delta \ln U N D E R V A L_{i t}+f_{i}+f_{t}+u_{i t}$,

where the dependent variable is annual growth in GDP per capita. The equation thus includes the standard convergence term (initial income per capita, $\left.R G D P C H_{i, t-1}\right)$ and a full set of country and time dummies $\left(f_{i}\right.$ and $\left.f_{t}\right)$. 
My primary interest is in the value of $\hat{\delta}$. Given the fixed-effects framework, what I am estimating is the "within" effect of undervaluation, namely, the impact of changes in under- or overvaluation on changes in growth rates within countries. I present regressions with additional covariates, as well as cross-sectional specifications, in a later subsection.

Table 1 presents the results. When estimated for the panel as a whole (column 1-1), the regression yields a highly significant $\hat{\delta}$ of 0.017 . However, as columns 1-2 and 1-3 reveal, this effect operates only for developing countries. In the richer countries in the sample, $\hat{\delta}$ is small and statistically indistinguishable from zero, whereas in the developing countries $\hat{\delta}$ rises to 0.026 and is highly significant. The latter estimate suggests that a 50 percent undervaluation - which corresponds roughly to one standard deviation in UNDERVAL - is associated with a boost in annual growth of real income per capita during the same five-year period of 1.3 percentage points $(0.50 \times$ $0.026)$. This is a sizable effect. I will discuss the plausibility of this estimate later, following my discussion of robustness tests and theoretical explanations.

The results in column 1-4 confirm further that the growth impact of undervaluation depends heavily on a country's level of development. When UNDERVAL is interacted with initial income, the estimated coefficient on the interaction term is negative and highly significant. The estimated coefficients in column 1-4 indicate that the growth effects of a 50 percent undervaluation for Brazil, China, India, and Ethiopia at their current levels of income are $0.47,0.60,0.82$, and 1.46 percentage points, respectively. The estimates also imply that the growth effect disappears at an income per capita of $\$ 19,635$, roughly the level of Bahrain, Spain, or Taiwan.

Interestingly, the estimated impact of undervaluation seems to be independent of the time period under consideration. When I split the developing country data into pre- and post-1980 subperiods (columns 1-5 and 1-6), the value of $\hat{\delta}$ remains basically unaffected. This indicates that the channel or channels through which undervaluation works have little to do with the global economic environment; the estimated impact is, if anything, smaller in the post-1980 era of globalization, when markets in rich countries were considerably more open. So the explanation cannot be a simple export-led growth story.

\section{Robustness: Sensitivity to Outliers}

As noted in the introduction, the literature on the relationship between exchange rate policy and growth has focused to date largely on the delete- 


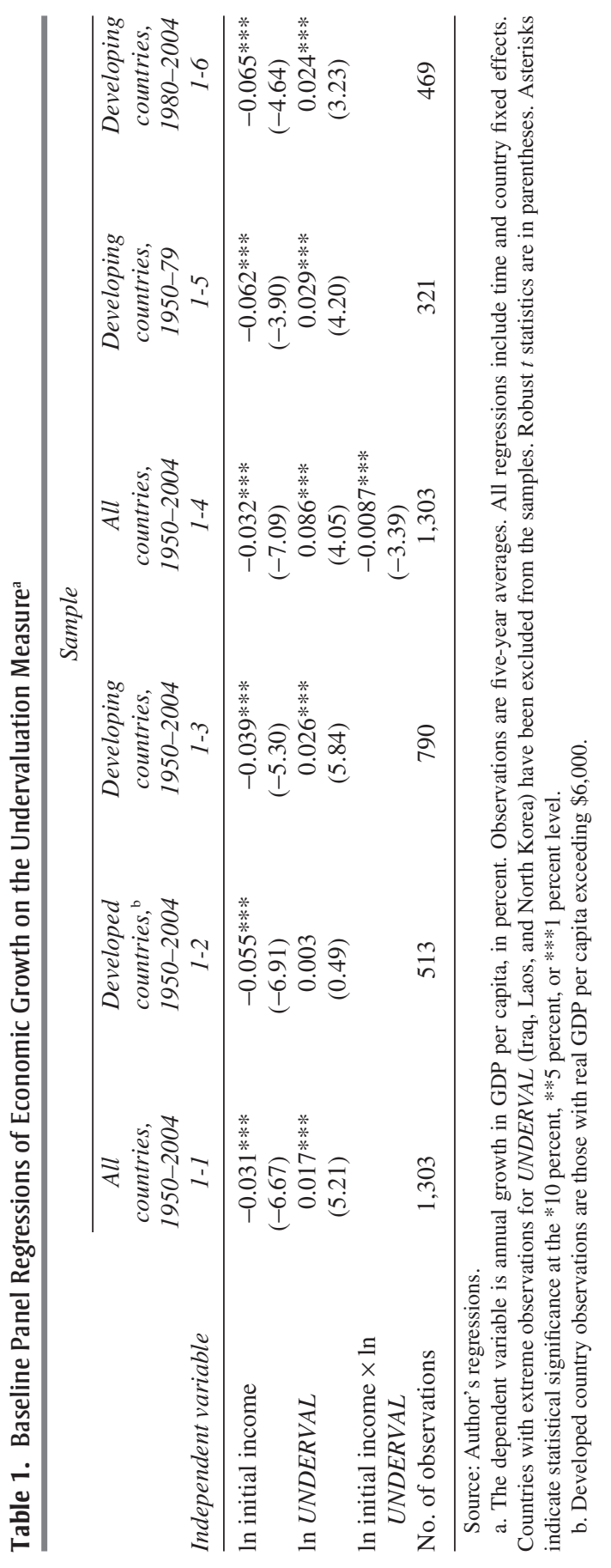


Figure 3. Growth and Undervaluation in the Developing Country Sample

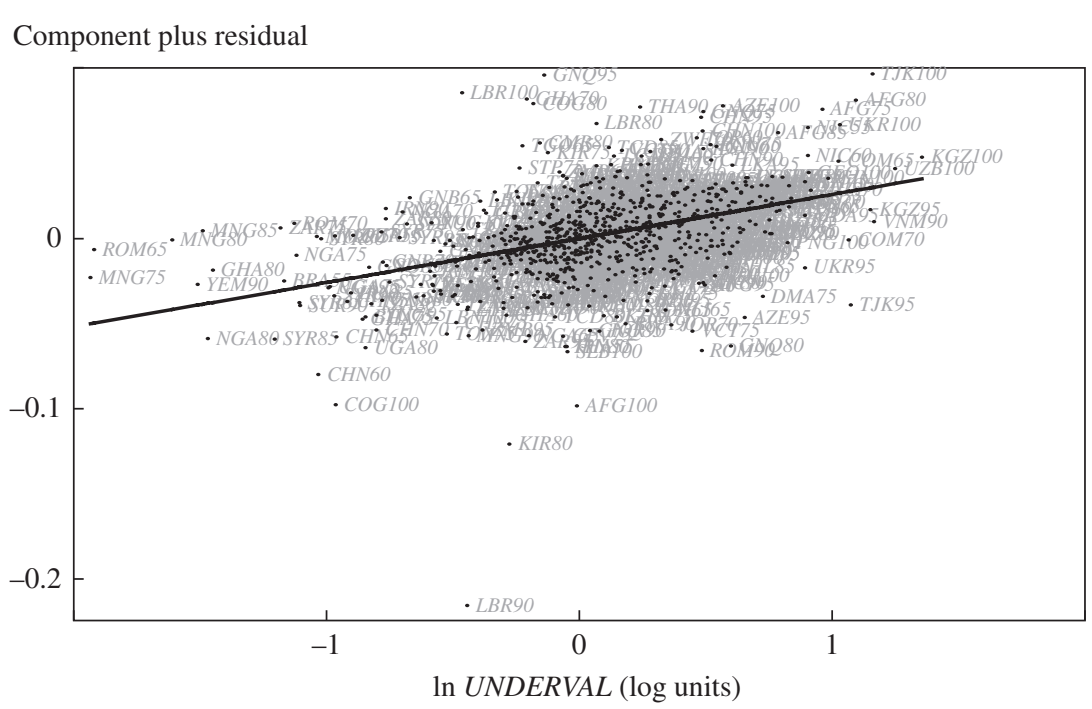

Sources: Penn World Tables version 6.2, and author's calculations.

rious consequences of large overvaluations. In his survey of the crossnational growth literature, Easterly warns against extrapolating from large black market premiums for foreign currency, for which he can find evidence of harmful effects on growth, to more moderate misalignments in either direction, for which he does not. ${ }^{13}$ However, the evidence strongly suggests that the relationship I have estimated does not rely on outliers: it is driven at least as much by the positive growth effect of undervaluation as by the negative effect of overvaluation. Furthermore, there is little evidence of nonlinearity in either direction.

Figure 3 presents a scatterplot of the data used in column 1-3 of table 1 (that is, developing countries over the entire sample period). Inspection suggests a linear relationship over the entire range of UNDERVAL and no obvious outliers. To investigate this more systematically, I ran the regression for successively narrower ranges of UNDERVAL. The results are shown in table 2, where the first column reproduces the baseline results from table 1, the second excludes all observations with UNDERVAL < -1.50 (that is, overvaluations greater than 150 percent), the third excludes observations with $U N D E R V A L<-1.00$, and so on. The final column 
Table 2. Impact of Excluding Extreme Observations of the Undervaluation Measure ${ }^{a}$

\begin{tabular}{lcccccc}
\hline & & \multicolumn{5}{c}{ Range of UNDERVAL included in sample } \\
\cline { 3 - 7 } & & $\begin{array}{c}\text { Greater } \\
\text { than }\end{array}$ & $\begin{array}{c}\text { Greater } \\
\text { than }\end{array}$ & $\begin{array}{c}\text { Greater } \\
\text { than }\end{array}$ & $\begin{array}{c}\text { Greater } \\
\text { than }\end{array}$ & $\begin{array}{c}\text { Between } \\
50 \% \text { and } \\
\end{array}$ \\
& Baseline & $-150 \%$ & $-100 \%$ & $-50 \%$ & $-25 \%$ & $-50 \%$ \\
\hline $\begin{array}{l}\text { Coefficient on } \\
\quad \text { ln UNDERVAL }\end{array}$ & 0.026 & 0.029 & 0.034 & 0.034 & 0.028 & 0.030 \\
$\begin{array}{l}t \text { statistic } \\
\text { No. of observations }\end{array}$ & $(5.84)$ & $(6.31)$ & $(7.28)$ & $(5.46)$ & $(4.32)$ & $(3.72)$ \\
\hline
\end{tabular}

Source: Author's regressions.

a. See table 1 for details of the specification. All estimated coefficients are statistically significant at the 1 percent level.

restricts the range to undervaluations or overvaluations that are smaller than 50 percent. The remarkable finding is that these sample truncations affect the estimated coefficient on ln UNDERVAL very little. The coefficient obtained when I eliminate all overvaluations greater than 25 percent is nearly identical to that for the entire sample, and the coefficient obtained when I eliminate all under- and overvaluations above 50 percent is still highly significant. Unlike Álvaro Aguirre and César Calderón, and Ofair Razin and Susan Collins, I find little evidence of nonlinearity in the relationship between undervaluation and economic growth. ${ }^{14}$

\section{Robustness: Different Real Exchange Rate Measures}

There are some potential concerns with relying exclusively on UNDER$V A L$ as a measure of under- or overvaluation. One issue is the uncertain reliability of the price-level measures in the Penn World Tables. As I mentioned above, the most recent revisions have revealed the estimates to be problematic in quite a few countries (even though the implications for changes over time within countries may not be as severe). This suggests the need to check the validity of my results using real exchange rate series constructed from other data sources.

Another worry relates to my adjustment for the Balassa-Samuelson effect. Although this adjustment is proper and introduces no bias when there is a direct feedback from incomes to price levels as indicated in equation 1, it may be problematic under some other circumstances. For example,

14. Aguirre and Calderón (2005); Razin and Collins (1997). I have also tried entering the square of UNDERVAL, distinguishing between positive and negative values of UNDER$V A L$. I find some evidence that extreme overvaluations (large negative values of UNDER$V A L)$ are proportionately more damaging to growth, but the effect is not that strong, and the main coefficient of interest remains unaffected. 
if the Balassa-Samuelson effect is created by a third variable ("productivity") that affects both income per capita and the price level, the coefficient estimates on UNDERVAL may be biased upward (as discussed by Michael Woodford in his comment on this paper). This suggests the need to employ alternative measures of the real exchange rate that do not incorporate the Balassa-Samuelson adjustment. Even though estimates from regressions that use such alternative measures are in turn likely to be biased downward (in the presence of Balassa-Samuelson effects that operate over time within countries), such estimates are still useful insofar as they provide a lower bound on the growth effects of undervaluation.

I therefore use four additional real exchange rate indices in the regressions that follow, to complement the results obtained with UNDERVAL above. First, I simply use the inverse of the index of the price level from the Penn World Tables, without the Balassa-Samuelson adjustment:

$$
\ln R E R_{P W T}=\ln \left(\frac{X R A T}{P P P}\right) .
$$

This measure has all the problems of the Penn World Tables, since it is constructed from that source, but for purposes of robustness testing it has the virtue that it is not subject to the sort of bias just mentioned. Next I use the real effective exchange rate index of the International Monetary Fund (IMF), ln $R E E R_{I M F}$, which is a measure of the value of home currency against a weighted average of the currencies of major trade partners divided by a price deflator or index of costs. This is a multilateral measure of competitiveness and is available for a large number of industrial and developing countries, although the coverage is not nearly as complete as that of the Penn World Tables. The third index is a simple bilateral measure of the real exchange rate with the United States, constructed using wholesale price indices:

$$
\ln R E R_{W P I}=\ln \left(\frac{E \times P P I_{U S}}{W P I}\right),
$$

where $E$ is the home country's nominal exchange rate against the U.S. dollar (in units of home currency per dollar), $P P I_{U S}$ is the producer price index for the United States, and WPI is the home country's wholesale price index. All of the data are from the IMF's International Financial Statistics (IFS). Since the IFS does not report wholesale price indices for many countries, I use as my final index a bilateral real exchange rate constructed using consumer prices: 


$$
\ln R E R_{C P I}=\ln \left(\frac{E \times P P I_{U S}}{C P I}\right),
$$

where $C P I$ is the home country's consumer price index. Note that the levels of the last three measures are not comparable across countries, but this is of no consequence for the panel regressions, which track the effects of changes in real exchange rates within countries.

Table 3 reports the results, for the full sample and the developing country sample separately, of rerunning the baseline specification from table 1 (columns 1-1 and 1-3), substituting in turn each of the above measures for UNDERVAL. The numbers tell a remarkably consistent story, despite the differences in data sources and in the construction of the index. When the regression is run on the full sample, the growth impact of a real depreciation is small and often statistically insignificant. But when the sample is restricted to developing countries (again defined as those with real GDP per capita below $\$ 6,000$ ), the estimated effect is strong and statistically significant in all cases. (Only the estimate using $R_{E E R_{I M F}}$ misses the 5 percent significance threshold, and that narrowly.) The coefficient estimates range between 0.012 and 0.029 (using $R E R_{C P I}$ and $R E R_{W P I}$, respectively) and bracket the estimate with UNDERVAL reported earlier (0.026). Note in particular that the coefficient estimate with $R E R_{P W T}$ is highly significant and, as expected, smaller than the estimate with UNDERVAL ( 0.016 versus 0.026). It is hard to say how much of this difference is due to the lack of correction for the Balassa-Samuelson effect (and hence a downward bias in the estimation when using $R E R_{P W T}$ ) and how much to the correction of a previous bias in the estimation with UNDERVAL. Even if the "correct" estimate is the lower one of 0.016 , it still establishes a strong enough relationship between real undervaluation and economic growth to command attention: a 50 percent undervaluation would boost annual growth of income per capita by 0.8 percentage point.

\section{Robustness: Additional Covariates}

The specifications reported thus far are rather sparse, including only a convergence factor, fixed effects, and the undervaluation measure itself. Of course, the fixed effects serve to absorb any growth determinants that are time-invariant and country-specific, or time-specific and countryinvariant. But it is still possible that some time-varying country-specific determinants correlated with UNDERVAL have been left out. The regressions reported in table 4 therefore augment the baseline specification with additional covariates. I include measures of institutional quality ("rule of 


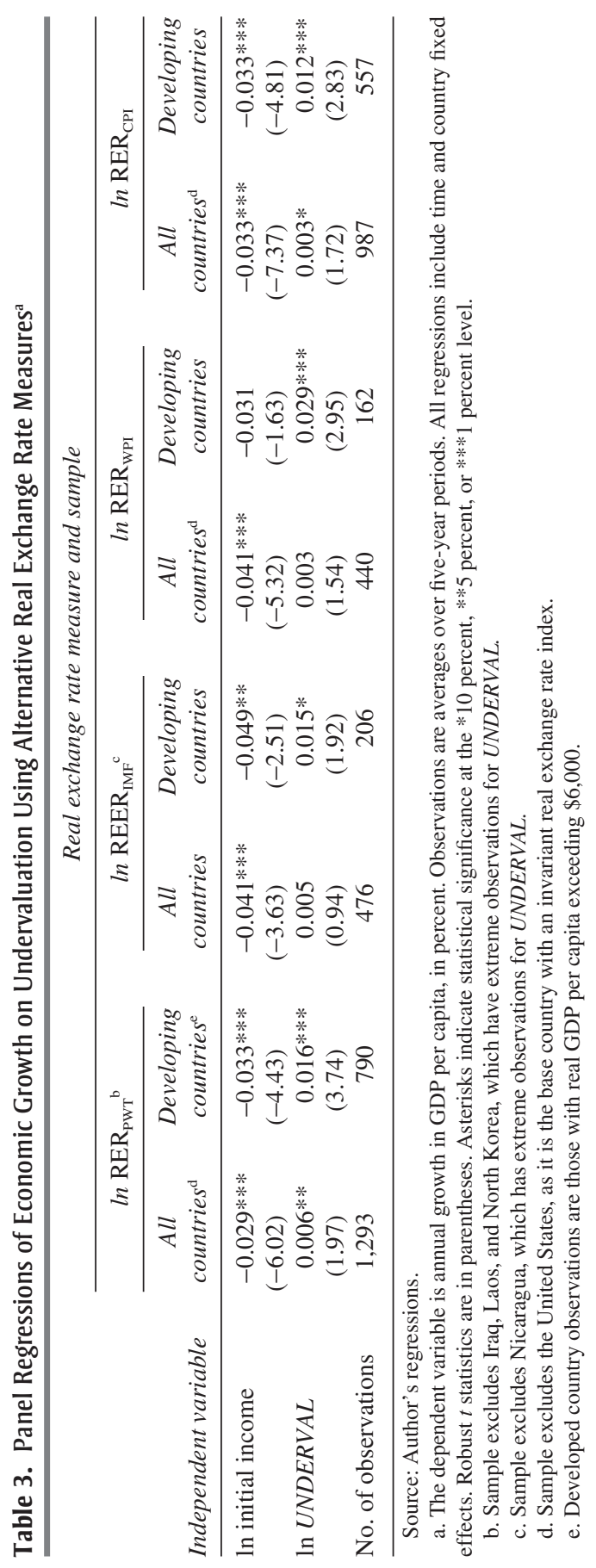




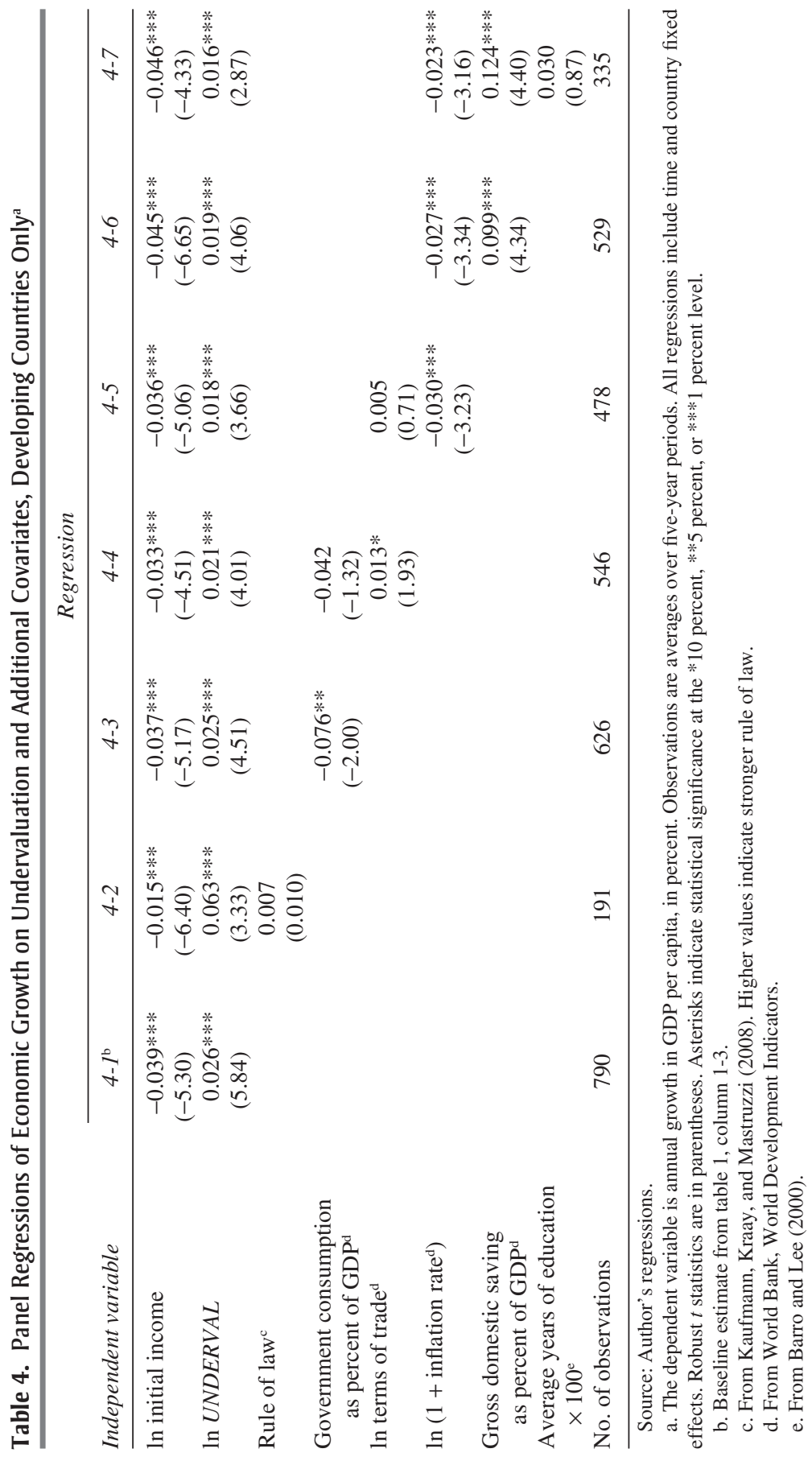


law"), government consumption, the external terms of trade, inflation, human capital (average years of education), and saving rates. ${ }^{15}$ One limitation here is that data for many of the standard growth determinants are not available over long stretches of time, so that many observations are lost as regressors are added. For example, the "rule of law" index starts only in 1996. Therefore, rather than include all the additional regressors simultaneously, which would reduce the sample size excessively, I tried various combinations, dropping those variables that seem to enter insignificantly or cause too many observations to be lost.

The bottom line is that including these additional regressors does not make much difference to the coefficient on UNDERVAL. The estimated coefficient ranges somewhat widely (from a high of 0.063 to a low of 0.016 ) but remains strongly significant throughout, with the $t$ statistic never falling below 2.8. The variation in these estimates seems to derive in any case as much from changes in the sample as from the effect of the covariates. Indeed, given the range of controls considered and the significant changes in sample size (from a low of 191 to a high of 790), the robustness of the central finding on undervaluation is quite striking. Note in particular that UNDERVAL remains strong even when the regression controls for changes in the terms of trade or government consumption (or both together), or for saving rates, three variables that are among the main drivers of the real exchange rate (see below).

\section{Robustness: Cross-Sectional Regressions}

As a final robustness check, I ran cross-sectional regressions using the full sample in an attempt to identify the growth effects of undervaluation solely through differences across countries. The dependent variable here is the growth rate of each country averaged over a twenty-five-year period (1980-2004). Undervaluation is similarly averaged over the same quarter century, and initial income is GDP per capita in 1980. Regressors include all the covariates considered in table 4 (except for the terms of trade) along with dummies for developing country regions as defined by the World Bank.

The results (table 5) are quite consistent with those in the vast empirical literature on cross-national growth. Economic growth over long time horizons tends to increase with human capital, quality of institutions, and

15. The data source for most of these variables is the World Bank's World Development Indicators. Data for the "rule of law" come from the World Bank governance dataset (Kaufmann, Kraay, and Mastruzzi, 2008), and those for human capital (years of education) from Barro and Lee (2000). 


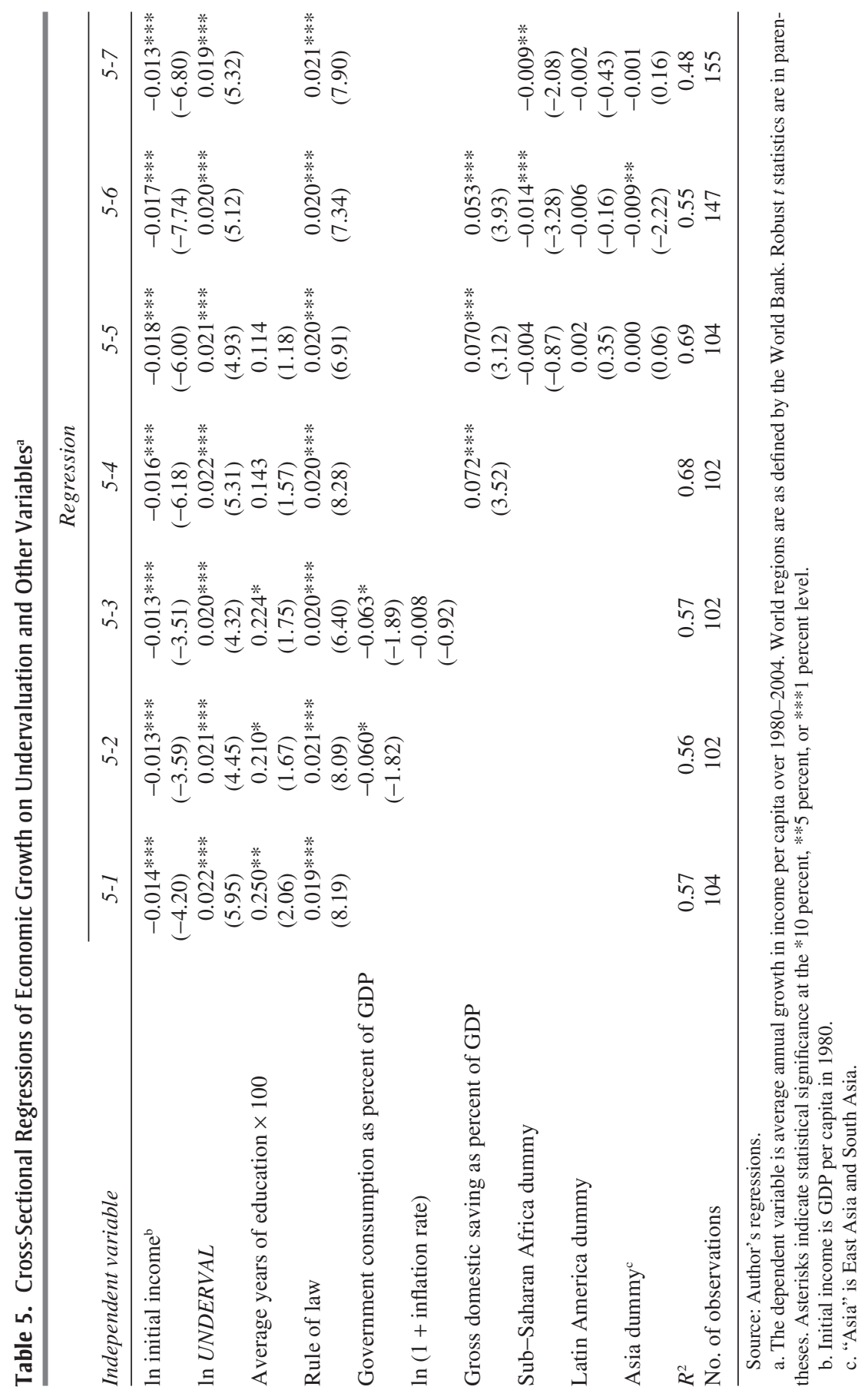


saving, and to decrease with government consumption and inflation. The Africa dummy tends to be negative and statistically significant. Interestingly, the Asia dummy is negative and significant in one regression that controls for saving rates (column 5-6) and not in the otherwise identical regression that does not (column 5-7). Most important for purposes of this paper, the estimated coefficient on UNDERVAL is highly significant and virtually unchanged in all these specifications, fluctuating between 0.019 and 0.022. It is interesting - and comforting-that these coefficient estimates and those obtained from the panel regressions are so similar.

Given the difficulty of controlling for all the country-specific determinants of growth, there are good reasons to distrust estimates from crosssectional regressions of this kind. That is why panels with fixed effects are my preferred specification. Nevertheless, the results in table 5 represent a useful and encouraging robustness check.

\section{Causality}

Another possible objection to these results is that the relationship they capture is not truly causal. The real exchange rate is the relative price of tradables to nontradables in an economy and as such is an endogenous variable. Does it then make sense to put it (or some transformation) on the right-hand side of a regression equation and talk about its effect on growth? Perhaps it would not in a world where governments did not care about the real exchange rate and left it to be determined purely by market forces. But we do not live in such a world: except in a handful of developed countries, most governments pursue a variety of policies with the explicit goal of affecting the real exchange rate. Fiscal policies, saving incentives (or disincentives), capital account policies, and interventions in currency markets are part of the array of such policies. In principle, moving the real exchange rate requires changes in real quantities, but economists have long known that even policies that affect only nominal magnitudes can do the trickfor a while. One of the key findings of the open-economy macroeconomic literature is that except in highly inflationary environments, nominal exchange rates and real exchange rates move quite closely together. Eduardo Levy-Yeyati and Federico Sturzenegger have recently shown that sterilized interventions can and do affect the real exchange rate in the short to medium term. ${ }^{16}$ Therefore, interpreting the above results as saying something about the growth effects of different exchange rate management strategies seems plausible.

16. Levy-Yeyati and Sturzenegger (2007). 
Of course, one still has to worry about the possibility of reverse causation and about omitted variables bias. The real exchange rate may respond to a variety of shocks besides policy shocks, and these may confound the interpretation of $\delta$. The inclusion of some of the covariates considered in tables 4 and 5 serves to diminish concern on this score. For example, an autonomous reduction in government consumption or an increase in domestic saving will both tend to produce a real depreciation, ceteris paribus. To the extent that such policies are designed to move the real exchange rate in the first place, they are part of what I have in mind when I talk of "a policy of undervaluation." But to the extent they are not, the results in tables 4 and 5 indicate that undervaluation is associated with faster economic growth even when those policies are controlled for.

A more direct approach is to treat UNDERVAL explicitly as an endogenous regressor; this is done in table 6 . Note first that a conventional instrumental variables approach is essentially ruled out here, because it is difficult to think of exogenous regressors that influence the real exchange rate without plausibly also having an independent effect on growth. I will report results of regressions on the determinants of UNDERVAL in table 10; all of the regressors used there have been used as independent variables in growth regressions. Here I adopt instead a dynamic panel approach using the generalized method of moments (GMM) as the estimation method. ${ }^{17}$ These models use lagged values of regressors (in levels and in differences) as instruments for right-hand-side variables and allow lagged endogenous (left-hand-side) variables as regressors in short panels. ${ }^{18}$ Table 6 presents results for both the "difference" and the "system" versions of GMM. As before, the estimated coefficients on UNDERVAL are positive and statistically significant for the developing countries (if somewhat at the lower end of the range reported earlier). They are not significant for the developed countries. Hence, when UNDERVAL is allowed to be endogenous, the resulting pattern of estimated coefficients is quite in line with the results reported above, which is reassuring.

It is worth reflecting on the sources of endogeneity bias a bit more. Many of the plausible sources of bias that one can think of would induce a negative relationship between undervaluation and growth, not the positive relationship I have documented. So to the extent that endogenous mechanisms are at work, it is not clear that they generally create a bias that works

17. I follow here the technique of Arellano and Bond (1991) and Blundell and Bond (1998).

18. See Roodman (2006) for an accessible user's guide. 


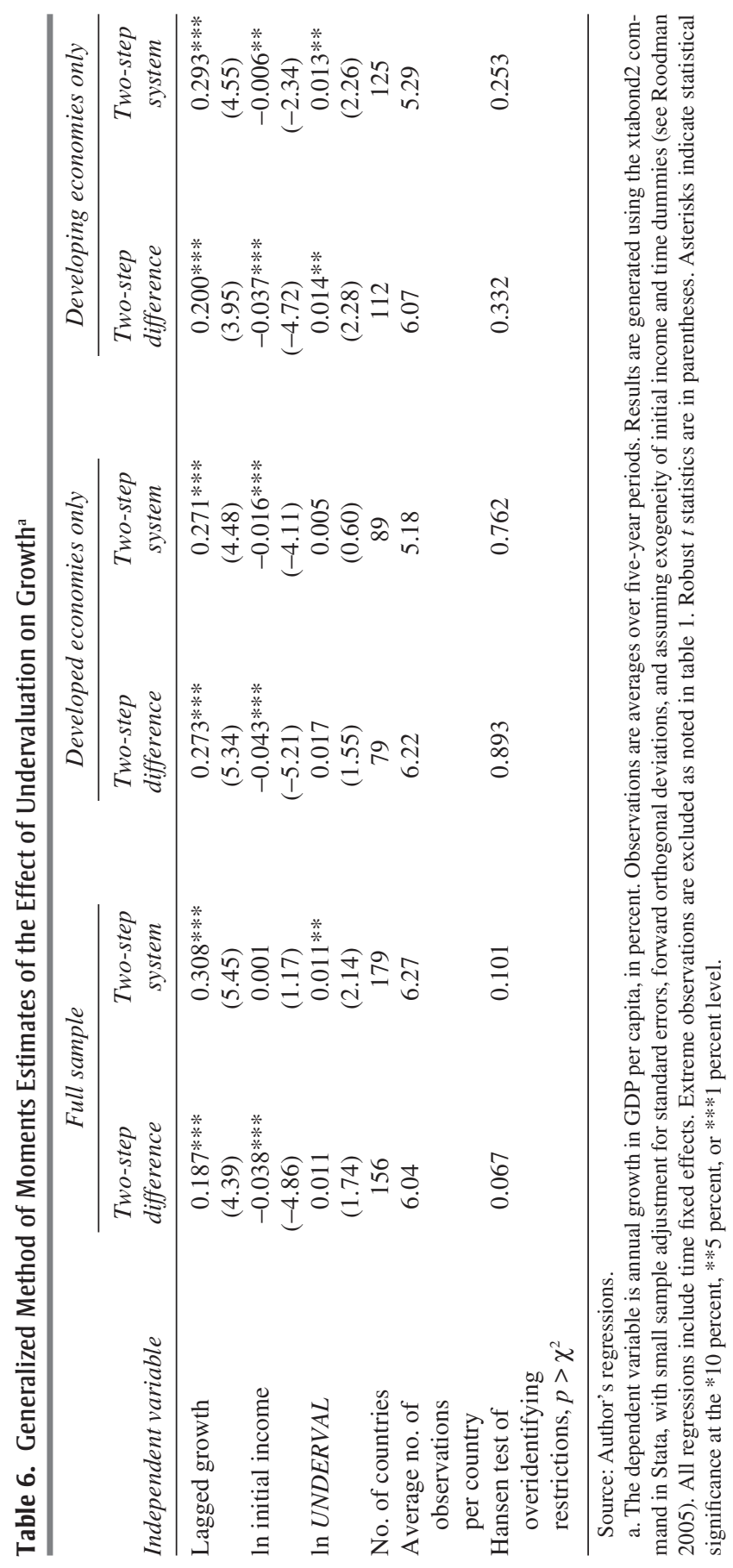


against my findings. Economic growth is expected to cause a real appreciation on standard Balassa-Samuelson grounds (which I control for by using UNDERVAL). Shocks that cause a real depreciation tend to be shocks that are bad for growth on conventional grounds-a reversal in capital inflows or a terms of trade deterioration, for example. Good news about the growth prospects of an economy is likely to attract capital inflows and thus bring about a real appreciation. So, on balance, it is unlikely that the positive coefficients reported here result from the reverse effect of growth on the real exchange rate.

\section{Evidence from Growth Accelerations}

A different way to look at the cross-national evidence is to examine countries that have experienced noticeable growth accelerations and ask what happened to UNDERVAL before, during, and after these episodes. This way of parsing the data throws out a lot of information but has the virtue that it focuses attention on a key question: have those countries that managed to engineer sharp increases in economic growth done so on the back of undervalued currencies? ${ }^{19}$

Ricardo Hausmann, Lant Pritchett, and I identified 83 distinct instances of growth acceleration in which annual growth in GDP per capita rose by 2 percentage points or more and the spurt was sustained for at least eight years. ${ }^{20}$ Figure 4 shows the average values of UNDERVAL in each of these episodes for a 21-year window centered on the year of the acceleration (the 10-year periods before and after the acceleration plus the year of the acceleration). The figure shows some interesting patterns in the trend of UNDERVAL but is especially telling with respect to the experience of different subgroups.

For the full sample of growth accelerations, a noticeable, if moderate, decline in overvaluation occurs in the decade before the onset of the growth spurt. The increase in UNDERVAL is on the order of 10 percentage points and is sustained into the first five years or so of the episode. Since these growth accelerations include quite a few rich countries in the 1950s and 1960s, figure 4 also shows results for only those growth accelerations in the sample that occurred after 1970. There is a much more distinct trend in UNDERVAL for this subsample: the growth spurt takes place after a decade of steady increase in UNDERVAL and immediately after the index reaches its peak value (at an undervaluation of 10 percent). Finally, figure 4 also

19. A similar exercise was carried out for a few, mostly Asian, countries by Hausmann (2006).

20. Hausmann, Pritchett, and Rodrik (2005). 
Figure 4. Relative Timing of Undervaluations and Growth Accelerations

Mean undervaluation (percent)

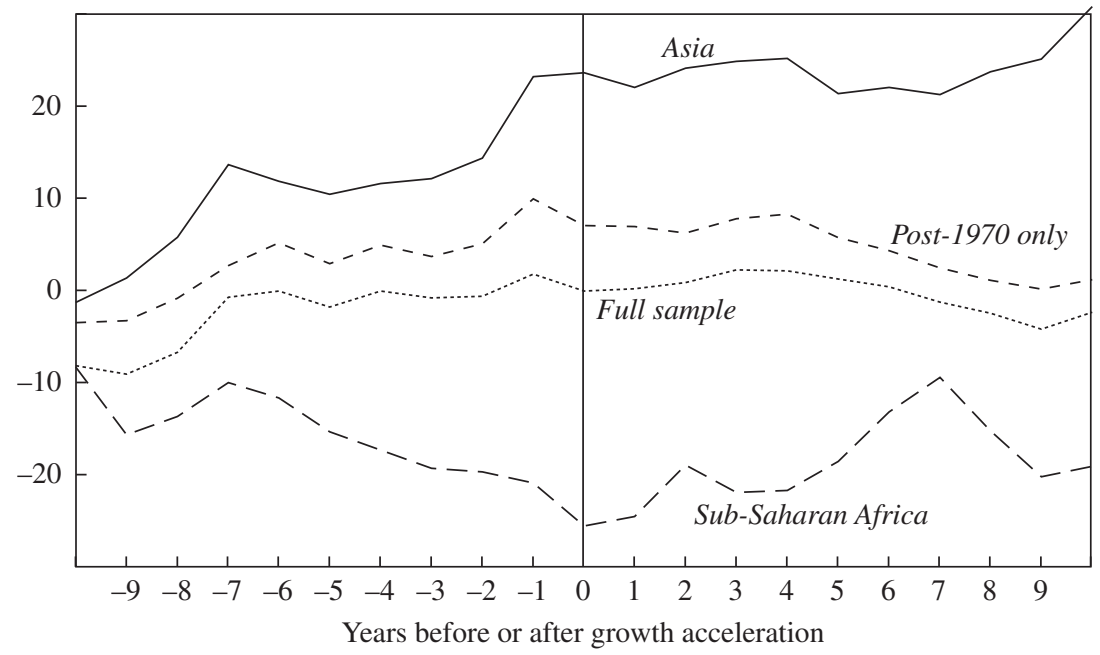

Source: Author's calculations.

shows results for the Asian and Sub-Saharan African countries separately. The Asian countries reveal the most pronounced trend, with an average undervaluation of more than 20 percent at the start of the growth acceleration. Moreover, the undervaluation is sustained into the growth episode, and in fact it increases further by the end of the decade. In the African growth accelerations, in contrast, the image is virtually the mirror opposite. Here the typical growth acceleration takes place after a decade of increased overvaluation, and its timing coincides with the peak of the overvaluation. As is well known, the Asian growth accelerations have proved significantly more impressive and lasting than African ones. The contrasting behavior of the real exchange rate may offer an important clue as to the sources of the difference.

\section{Size of the Tradable Sector as the Operative Channel}

The real exchange rate is a relative price, the price of tradable goods in terms of nontradable goods:

$$
R E R=P_{T} / P_{N} .
$$

An increase in RER enhances the relative profitability of the tradable sector and causes it to expand (at the expense of the nontradable sector). 
I now provide some evidence that these compositional changes in the structure of economic activity are an important driving force behind the empirical regularity I have identified. I show two things in particular. First, undervaluation has a positive effect on the relative size of the tradable sector, and especially of industrial economic activities. Second, the effects of the real exchange rate on growth operate, at least in part, through the associated change in the relative size of tradables. Countries where undervaluation induces resources to move toward tradables (again, mainly industry) grow more rapidly.

The first four columns in table 7 report standard panel regressions where five-year-average sectoral shares (in real terms) are regressed on income, a complete set of fixed effects, and my measure of undervaluation. I initially lumped agriculture and industry together in constructing the dependent variable, since both are nominally tradable, but as these regressions show, they have quite a different relationship with real exchange rates. Whether measured by its share in GDP or its share in employment, the relative size of industry depends strongly and positively on the degree of undervaluation as shown in the first two columns. ${ }^{21}$ Simply put, undervaluation boosts industrial activities. Agriculture, on the other hand, does not have a positive relationship with undervaluation. Its GDP share actually depends negatively on the undervaluation measure (third column). This difference may reflect the prevalence of quantitative restrictions in agricultural trade, which typically turn many agricultural commodities into nontradables at the margin.

The last two columns of table 7 report results of two-stage panel growth regressions (with, as before, a full set of fixed effects) that test whether the effect of undervaluation on growth operates through its impact on the relative size of industry. The strategy consists of identifying whether the component of industrial shares directly "caused" by undervaluation - that is, industrial shares as instrumented by undervaluation - enters positively and significantly in the growth regressions. The answer is affirmative. These results indicate that undervaluation causes resources to move toward industry and that this shift in resources in turn promotes economic growth. ${ }^{22}$

21. Blomberg, Frieden, and Stein (2005) report some evidence that countries with larger manufacturing sectors have greater difficulty in sustaining currency pegs. But it is not immediately evident which way this potential reverse causality cuts.

22. See also the supporting evidence in Rajan and Subramanian (2006), who find that real appreciations induced by aid inflows have adverse effects on the relative growth rate of exporting industries as well as on the growth rate of the manufacturing sector as a whole. Rajan and Subramanian argue that this is one of the more important reasons why aid fails to 


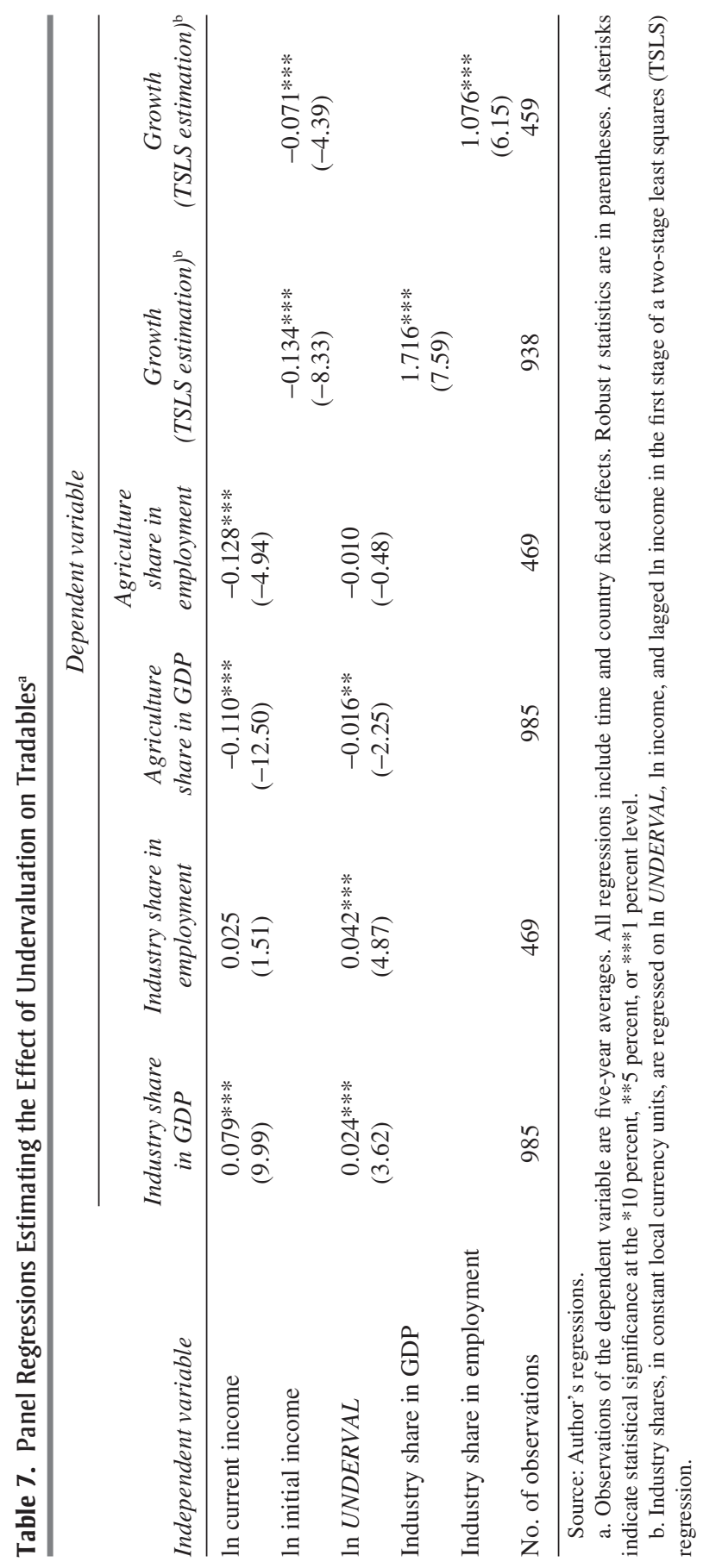


The estimates in table 7 also provide a useful check on the quantitative magnitudes involved. They break the undervaluation-growth relationship into two separate links, one from undervaluation to the size of tradables (that is, industry) and the other from the size of industry to economic growth. If undervaluation has a potent effect on growth, that is because each of these two links is estimated to be quite strong. A 50 percent undervaluation is estimated to increase the share of industry in total employment by 2.1 percentage points $(0.042 \times 0.50)$, which is quite large given that the typical share of industry in total employment in developing countries is around 20 percent. An increase in the industrial employment share is in turn estimated to raise growth roughly one for one.

\section{Understanding the Importance of the Real Exchange Rate}

Why might an increase in the relative price of tradables and the associated expansion of tradable economic activities have a causal impact on economic growth, as my results suggest? There is no generally accepted theory that would explain these regularities in the data. ${ }^{23}$ Any such theory would have to explain why tradables are "special" from the standpoint of growth. That is the sense in which my results open an important window on the mechanisms behind the growth process. If the role that tradables play in driving growth can be understood, it may be possible to identify policies that will promote (and those that will hamper) growth.

Although any of a large number of stories might account for the role of tradables, two clusters of explanations deserve attention in particular. One focuses on weaknesses in the contracting environment, and the other on market failures in modern industrial production. Both types of explanation have been common in the growth and development literature, but in the present context something more is needed. One has to argue that tradables

induce growth in recipient countries. Gluzmann, Levy-Yeyati, and Sturzenegger (2007), by contrast, find little role for the tradables channel and argue that real undervaluations promote growth through redistributions of income that raise domestic saving (and ultimately investment). However, their argument seems to require that the current account be invariant to the real exchange rate, which is contradicted by considerable evidence. See also Galvarriato and Williamson (2008) on the role played by favorable relative prices in the rapid industrialization of Latin American countries such as Brazil and Mexico after 1870, and Freund and Pierola (2008) on the significance of currency undervaluation in stimulating export surges.

23. In Rodrik (1986) I argued that manipulating the real exchange rate could play a welfare-enhancing role if this served to improve the internal terms of trade of sectors subject to dynamic learning externalities. Gala (2007) suggests that undervaluation is good for growth because activities subject to increasing returns tend to be located in the tradable rather than the nontradable sector. 
Figure 5. Undervaluation as a Second-Best Mechanism for Alleviating Institutional Weakness

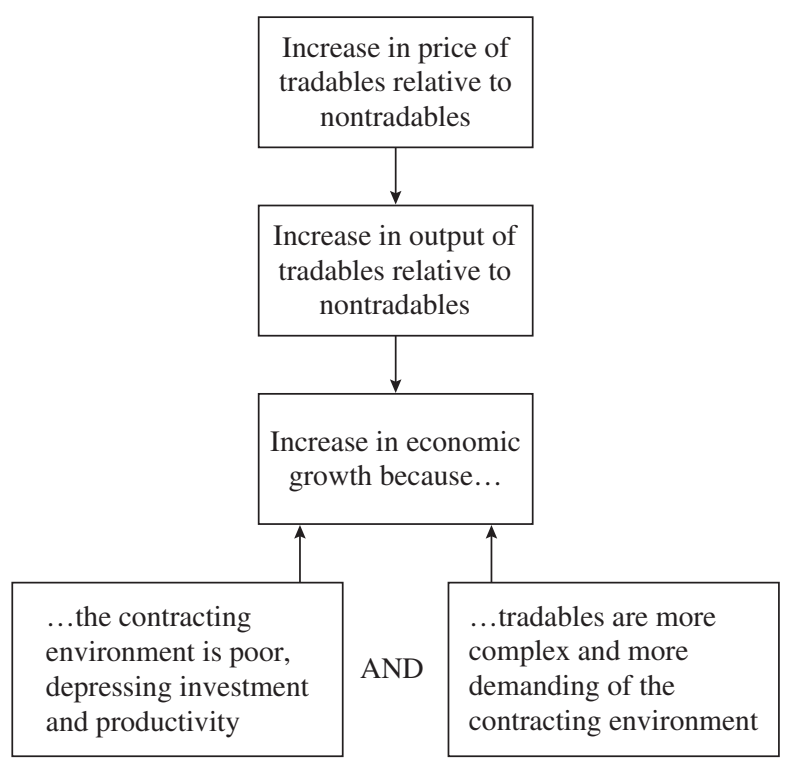

Source: Author's model described in the text.

suffer disproportionately from these shortcomings, so that absent a compensating policy, developing economies devote too few of their resources to tradables and thus grow less rapidly than they should. Real undervaluation can then act as a second-best mechanism for spurring growth of tradables and for generating more rapid overall economic growth.

The two clusters of explanations are represented schematically in figures 5 and 6. I discuss them in turn in the rest of this section. The mechanics of how changes in relative prices can generate growth in the presence of sectorally differentiated distortions is discussed in the following section.

\section{Explanation 1: Bad Institutions “Tax” Tradables More}

The idea that poor institutions keep incomes low and explain, at least in part, the absence of economic convergence is by now widely accepted. ${ }^{24}$ Weak institutions reduce the ability of private investors to appropriate the returns on their investment through a variety of mechanisms: contractual

24. North (1990); Acemoglu, Johnson, and Robinson (2001). 
Figure 6. Undervaluation as a Second-Best Mechanism for Alleviating Market Failure

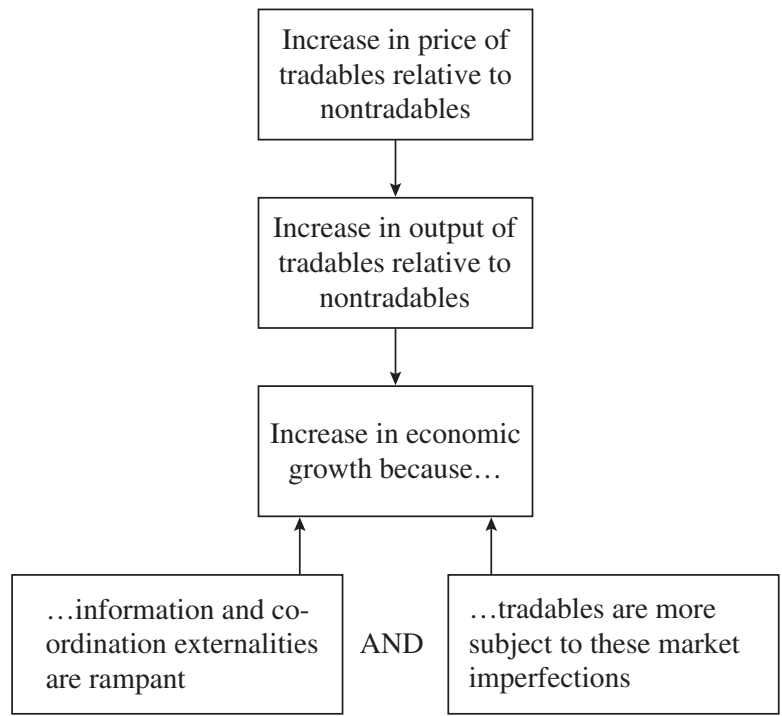

Source: Author's model described in the text.

incompleteness, hold-up problems, corruption, lack of property rights, and poor contract enforcement. The resulting wedge between private and social returns in turn blunts the incentives for capital accumulation and technological progress alike.

Now suppose that this problem is more severe in tradables than in nontradables. This is a plausible supposition since production systems tend to be more complex and roundabout in tradables, placing a greater premium on the ability to specify contracts and on reliable third-party enforcement of contracts. A barber needs to rely on little more than a few tools, a chair, and his skill and ingenuity to sell his services. A manufacturing firm needs the cooperation of multitudes of suppliers and customers, plus financial and legal support. When the institutions that foster these relationships are weak, the result is to impose a higher "tax" on tradables-especially modern tradables. This results in both a static misallocation of resources that penalizes tradables, and a dynamic distortion in the form of investment in tradables that is lower than socially optimal. An increase in the relative price of tradables can improve static efficiency and enhance growth in second-best fashion by eliciting more investment in tradables at the margin (as I will show in the following section). 
A fair amount of empirical work, both across countries and across industries, presents suggestive evidence on the disproportionate cost borne by tradables - as a whole or in part - in the presence of weak institutions:

-Across countries, lower quality of institutions (as measured by indices of the rule of law, contract enforcement, or control of corruption) is associated with lower ratios of trade to GDP ("openness"). ${ }^{25}$

-Across different categories of tradable goods, more "institutionintensive" tradables are prone to larger effects. Pierre-Guillaume Méon and Khalid Sekkat find that the relationship they identify holds for manufactured exports but not for nonmanufactured exports; Priya Ranjan and Jae Young Lee find that the effect is stronger for differentiated goods than for homogeneous goods. ${ }^{26}$

-Institutional weakness interacts with the contract intensity of goods to play a role in determining comparative advantage. Andrei Levchenko; Daniel Berkowitz, Johannes Moenius, and Katharina Pistor; and Nathan Nunn find that countries with poor institutions have comparative disadvantage in products that are more institutions-intensive, more complex, or more relationship-intensive. ${ }^{27}$

To provide more direct evidence, I used unpublished data kindly provided by Nathan Nunn to compare directly the contract-intensiveness of tradables and nontradables. Nunn investigated whether differences in institutional quality across countries help determine patterns of comparative advantage. ${ }^{28}$ He reasoned that relationship-specific intermediate inputs, defined as inputs that are not sold on exchanges or do not have reference prices, ${ }^{29}$ are more demanding of the contractual environment. Nunn used measures of relationship specificity for tradables alone, since his main concern was with comparative advantage. But he collected similar data for services as well, which are what I use to carry out the tradables-nontradables comparison.

The top panel of table 8 shows the shares of intermediate goods that are relationship-specific in tradables and nontradables industries. (These numbers are based on the U.S. input-output tables.) At first sight, these numbers seem to conflict with what my argument requires, in that they show that the

25. See, for example, Anderson and Mercouiller (2002), Rodrik, Subramanian, and Trebbi (2004), Rigobon and Rodrik (2005), Méon and Sekkat (2006), Berkowitz, Moenius, and Pistor (2006), and Ranjan and Lee (2004).

26. Méon and Sekkat (2006); Ranjan and Lee (2004).

27. Levchenko (2004); Berkowitz, Moenius, and Pistor (2006); Nunn (2007).

28. Nunn (2007).

29. As in Rauch (1999). 
Table 8. Illustrative Calculations on the Importance of Relationship Specificity of Inputs for Traded and Nontraded Goods

Percent

Tradables

Nontradables

Tradables use intermediate goods that tend to

be less relationship specific...

Share of intermediates not sold on exchanges

49.6

and not reference-priced ${ }^{a}$

Share of intermediates not sold on exchanges ${ }^{\mathrm{a}}$

87.3

96.4

... but tradables rely more on intermediate inputs . . .

Share of intermediates in total output ${ }^{\mathrm{b}}$

64.3

35.1

Share of interindustry sales in total output ${ }^{\mathrm{b}}$

58.4

29.4

... so, on balance, relationship-specific

intermediate goods account for a much

larger share of output in tradables.

Share in gross output of intermediates not

sold on exchanges and not reference-priced ${ }^{c}$

Share in gross output of intermediates

31.5

not sold on exchanges ${ }^{c}$

Source: Author's calculations.

a. Unweighted averages, from the U.S. input-output tables, calculated using data provided by Nathan Nunn, based on Nunn (2007).

b. From the Brazilian input-output tables for 1996, available on the website of the OECD Directorate for Science, Technology, and Industry (www.oecd.org/sti).

c. Sums of the products of the underlying data in the top two panels weighted by U.S. value-added shares.

inputs used in tradables are less relationship-specific, and hence less demanding of the institutional environment. But this is misleading because it overlooks the fact that tradables tend to have much higher intermediate input shares in gross output. This is shown in the middle panel of the table (this time relying on Brazil's input-output tables). Putting the two pieces together yields the results in the bottom panel of table 8, which show that, on balance, tradable goods rely on relationship-specific inputs to a much greater extent. The numbers for the two sets of goods differ by a factor of between two and three.

Hence the evidence that institutional and contracting shortcomings, the bane of every developing society, impose a higher "tax" on the tradable sector than on the nontradable sector is fairly compelling. But if this story is correct, its implications should also be evident in the growth regressions. Specifically, the growth impact of undervaluation should be greater in those countries where this "taxation" is greatest, namely, the countries 
with the weakest institutions. Although GDP per capita does track institutional quality closely, it is not a perfect proxy. So the question is whether one can detect the differential impact in settings with different institutional environments.

To attempt this more direct test, I used the World Bank governance indices to divide the countries in the full sample into three subgroups based on their "adjusted" institutional quality (above average, around average, and below average). ${ }^{30}$ The exercise was conducted as follows. For each country I took a simple average of the World Bank's rule of law, government effectiveness, regulatory quality, and corruption indices over 19962004 (starting from the earliest year for which these indices are available). I then regressed these indices on log GDP per capita, generating a predicted value based on this cross section. Taking the difference between actual and predicted values, I ranked countries according to their "adjusted" levels of institutional quality. I then divided the sample into three subgroups of equal size.

The middle three columns of table 9 show the results of my benchmark specification when the regression is run for each subgroup separately. (For comparison, the first column repeats the baseline results from column 1-1 of table 1.) The results are broadly consistent with the theoretical expectation. The positive effect of undervaluation is strongest in the below-average group and virtually nil in the above-average group. In other words, when initial income is taken into account, undervaluation works most potently in those countries where institutions perform the least well. In the last column in table 9, I instead interact dummies for the subgroups with UNDERVAL (taking the above-average group as the omitted category), and the results are very similar.

The analytics of how institutional weakness interacts with undervaluation to influence growth will be developed further in the next section. But first I turn to the second category of explanations.

\section{Explanation 2: Market Failures Predominate in Tradables}

The second hypothesis for why the real exchange rate matters is that tradables are particularly prone to the market failures with which development economists have long been preoccupied. A short list of such market failures would include

-learning externalities: valuable technological, marketing, and other information spills over to other firms and industries;

30. For the latest version of these indices see Kaufmann, Kraay, and Mastruzzi (2008). 
Table 9. Institutional Quality and the Impact of Undervaluation on Growth ${ }^{\mathrm{a}}$

\begin{tabular}{|c|c|c|c|c|c|}
\hline \multirow[b]{2}{*}{ Independent variable } & \multirow{2}{*}{$\begin{array}{l}\text { Baseline } \\
\quad \text { (all } \\
\text { countries) }\end{array}$} & \multicolumn{3}{|c|}{ Countries where institutional quality is } & \multirow{2}{*}{$\begin{array}{c}\text { Interactions } \\
\text { with group } \\
\text { dummies } \\
\quad \text { (all } \\
\text { countries) }\end{array}$} \\
\hline & & $\begin{array}{c}\text { Above } \\
\text { average }\end{array}$ & $\begin{array}{l}\text { Around } \\
\text { average }\end{array}$ & $\begin{array}{c}\text { Below } \\
\text { average }\end{array}$ & \\
\hline ln initial income & $\begin{array}{l}-0.031^{* * *} \\
(-6.67)\end{array}$ & $\begin{array}{l}-0.036^{* * *} \\
(-5.59)\end{array}$ & $\begin{array}{l}-0.017 \text { ** } \\
(-2.32)\end{array}$ & $\begin{array}{l}-0.060 \text { *** } \\
(-4.73)\end{array}$ & $\begin{array}{l}-0.031 \text { *** } \\
(-6.90)\end{array}$ \\
\hline $\ln U N D E R V A L$ & $\begin{array}{l}0.017 * * * \\
(5.21)\end{array}$ & $\begin{array}{c}0.004 \\
(1.17)\end{array}$ & $\begin{array}{l}0.022 * * * \\
(3.98)\end{array}$ & $\begin{array}{l}0.028 * * * \\
(4.42)\end{array}$ & $\begin{array}{c}0.005 \\
(1.45)\end{array}$ \\
\hline $\begin{array}{l}\text { In } U N D E R V A L \times \\
\text { around-average } \\
\text { institutions }\end{array}$ & & & & & $\begin{array}{l}0.019 \text { *** } \\
(2.86)\end{array}$ \\
\hline $\begin{array}{l}\text { In } U N D E R V A L \times \\
\text { below-average } \\
\text { institutions }\end{array}$ & & & & & $\begin{array}{l}0.019 * * \\
(2.36)\end{array}$ \\
\hline No. of observations & 1,303 & 513 & 434 & 356 & 1,303 \\
\hline
\end{tabular}

Source: Author's regressions.

a. The dependent variable is annual growth in GDP per capita, in percent. Observations are five-year averages. All regressions include time and country fixed effects. Robust $t$ statistics are in parentheses. Asterisks indicate statistical significance at the $* 10$ percent, $* * 5$ percent, or $* * * 1$ percent level.

-coordination externalities: getting new industries off the ground requires lumpy and coordinated investments upstream, downstream, or sideways;

-credit market imperfections: entrepreneurs cannot finance worthwhile projects because of limited liability and asymmetric information;

-wage premiums: monitoring, turnover, and other costs keep wages above market-clearing levels, and employment remains low.

These and similar problems can plague all kinds of economic activity in developing countries, but arguably their effects are felt much more acutely in tradables. If so, output and investment in tradables will be suboptimal. A real depreciation would promote capacity expansion in tradables and increase growth. Note that once again this is a second-best argument for undervaluation. First-best policy would consist of identifying distinct market failures and applying the appropriate Pigovian remedies. Undervaluation is in effect a substitute for industrial policy.

What is the evidence? By their very nature, the types of market failures listed above are difficult to identify, and so it is practically impossible to provide direct evidence that some kinds of goods are more prone to these market failures than others. But the basic hypothesis is quite plausible, and a close look at the processes behind economic development yields plenty 
of indirect and suggestive evidence. Economic development consists of structural change, investment in new activities, and the acquisition of new productive capabilities. As countries grow, the range of tradable goods that they produce expands. ${ }^{31}$ Rich countries are rich not just because they produce traditional goods in greater abundance, but also because they produce different goods. ${ }^{32}$ The market failures listed above are likely to be much more severe in new lines of production - those needed to increase economywide productivity - than in traditional ones. New industries require "cost discovery, ${ }^{33}$ learning-by-doing, and complementary economic activities to get established. They are necessarily risky and lack track records. These features make them fertile ground for learning and coordination externalities. The recent findings of Caroline Freund and Martha Pierola are particularly suggestive in this connection: currency undervaluation appears to play a very important role in inducing producers from developing countries to enter new product lines and new markets, and this seems to be the primary mechanism through which they generate export surges. ${ }^{34}$

\section{Discussion}

Unfortunately, it is not easy to distinguish empirically between the two broad hypotheses I have outlined. In principle, if one could identify the goods that are most affected by each of these two categories of imperfections-contractual and market failures-one could run a horse race between the two hypotheses by asking which goods among them are more strongly associated with economic growth. Nunn's data are a useful beginning for ranking goods by degree of contract intensity ${ }^{35}$ Perhaps an analogous set of rankings could be developed for market failures using the commodity categorization in Hausmann and Rodrik, ${ }^{36}$ which are loosely based on the prevalence of learning externalities. But ultimately I doubt that one can make a sufficiently fine and reliable distinction among goods to allow discrimination between the two stories in a credible manner. Rich countries differ from poor countries both because they have better institutions and because they have learned how to deal with market imperfections. Producers of tradable goods in developing economies suffer on both counts.

31. Imbs and Wacziarg (2003).

32. Hausmann, Hwang, and Rodrik (2007).

33. Hausmann and Rodrik (2003).

34. Freund and Pierola (2008).

35. Nunn (2007).

36. Hausmann and Rodrik (2003). 


\section{A Simple Model of Real Exchange Rates and Growth}

I argued in the previous section that when tradables are affected disproportionately by preexisting distortions, a real depreciation can be good for growth. I now develop a simple model to illustrate the mechanics behind this hypothesis. I will consider an economy in which there exist "taxes" on both the tradable and the nontradable sectors that drive a wedge between the private and the social marginal benefits. When the tax on tradables is larger (in ad valorem terms) than the tax on nontradables, the economy's resources will be misallocated, the tradable sector will be too small, and growth will be suboptimal. Under these circumstances a real depreciation can promote growth.

\section{Consumption and Growth}

In the model, consumers consume a single final good, which as shown below is produced using a combination of tradable and nontradable inputs. Their intertemporal utility function is time-separable and logarithmic and takes the form

$$
u=\int \ln c_{t} e_{t}^{-\rho} d t
$$

where $c_{t}$ is consumption at time $t$ and $\rho$ is the discount rate. Maximizing utility subject to an intertemporal budget constraint yields the familiar growth equation

$$
\dot{c}_{t} / c_{t}=r_{t}-\rho
$$

where $r$ is the real interest rate (or the marginal product of capital). The economy's growth is increasing in $r$, and this is the feature that I will exploit in the rest of this section.

\section{Production}

I assume that the economy produces the single final good using tradable and nontradable goods $\left(y_{T}\right.$ and $y_{N}$, respectively) as the sole inputs. Production of the final good $(y)$ is a Cobb-Douglas aggregate of these two inputs. In addition, to allow for endogenous growth (while maintaining perfect competition throughout), I assume that capital produces external economies in the production of the final good. With these assumptions, the production function of the representative final-good producer can be written as follows:

$$
y=\bar{k}^{1-\varphi} y_{T}^{\alpha} y_{N}^{1-\alpha}
$$


where $k$ is the economy's capital stock at any point in time (treated as exogenous by each final-goods producer), and $\alpha$ and $1-\alpha$ are the shares of tradable and nontradable goods, respectively, in the production costs of the final good $(0<\alpha<1)$. For convenience, I choose the exponent on $k$ to be a parameter $(1-\varphi)$ that will make aggregate output linear in capitalas will be shown shortly-and which therefore considerably simplifies the comparative dynamics of the model. I also omit time subscripts to simplify the notation.

Tradables and nontradables are in turn produced using capital alone and subject to decreasing returns to scale. These production functions take the following simple form:

$$
\begin{gathered}
q_{T}=A_{T} k_{T}^{\varphi}=A_{T}\left(\theta_{T} \bar{k}\right)^{\varphi} \\
q_{N}=A_{N} k_{N}^{\varphi}=A_{N}\left[\left(1-\theta_{T}\right) \bar{k}\right]^{\varphi},
\end{gathered}
$$

where $k_{T}$ and $k_{N}$ denote the capital stock employed in the tradables and the nontradables sectors, respectively; $\theta_{T}$ is the share of total capital employed in tradables and $0<\theta_{T}<1$; and $0<\varphi<1$. To justify decreasing returns to capital in the sectoral production functions (that is, $\varphi<1$ ), one can suppose that there are other, sector-specific factors of production employed in each sector that are fixed in supply.

By definition, nontradables that are used as inputs in the final-goods sector can only be sourced domestically. And since nontradables do not enter consumption directly,

$$
q_{N}=y_{N}
$$

With respect to tradables, I allow the economy to receive a transfer from the rest of the world (or to make a transfer to it). Let $b$ stand for the magnitude of the inward transfer. Then the material-balances equation in tradables is given by

$$
q_{T}+b=y_{T} .
$$

It will be more convenient to express $b$ as a share $\gamma$ of total domestic demand for tradables. That is, $b=\gamma y_{T}$. The equality between demand and supply in tradables then becomes

$$
\frac{1}{1-\gamma} q_{T}=y_{T}
$$


When the economy makes an outward transfer, $\gamma$ will be negative. I will use $\gamma$ as a shifter that alters the equilibrium value of the real exchange rate.

Using equations 4 through 8 , one can express the aggregate production function as

$$
y=(1-\gamma)^{-\alpha} A_{T}^{\alpha} A_{N}^{1-\alpha} \theta_{T}^{\alpha \varphi}\left(1-\theta_{T}\right)^{(1-\alpha) \varphi} \bar{k} .
$$

Net output $\tilde{y}$ differs from gross output insofar as the economy makes a payment to the rest of the world for the transfer $b$ (or receives a payment from it if $b$ is negative). I express this payment in general form, assuming that it is a share $\sigma$ of the transfer's contribution to gross output; that is, $\sigma \times$ $(\partial y / \partial b) \times b=\sigma \times\left(\partial y / \partial y_{T}\right) \times \gamma y_{T}=\sigma \times\left(\alpha / y_{T}\right) y \times \gamma y_{T}=\sigma \alpha \gamma y$. Net output $\tilde{y}$ equals $y-\sigma \alpha \gamma y=(1-\sigma \alpha \gamma) y$. Therefore, using equation 9 ,

$$
\tilde{y}=(1-\sigma \alpha \gamma)(1-\gamma)^{-\alpha} A_{T}^{\alpha} A_{N}^{1-\alpha} \theta_{T}^{\alpha \varphi}\left(1-\theta_{T}\right)^{(1-\alpha) \varphi} \bar{k} .
$$

This way of expressing the payment for the transfer allows a wide variety of scenarios. The transfer's contribution to net output is maximized when $\sigma=0$, that is, when $b$ is a pure transfer (a grant). The contribution becomes smaller as $\sigma$ increases.

Note that the production function ends up being of the $A k$ type, that is, linear in capital. This results in an endogenous growth model with no transitional dynamics. The (net) marginal product of capital $r$ is $\partial \tilde{y} / \partial \bar{k}$, or

$$
r=(1-\sigma \alpha \gamma)(1-\gamma)^{-\alpha} A_{T}^{\alpha} A_{N}^{1-\alpha} \theta_{T}^{\alpha \varphi}\left(1-\theta_{T}\right)^{(1-\alpha) \varphi},
$$

which is independent of the capital stock but depends on the allocation of capital between tradables and nontradables, $\theta_{T}$, as well as on the net value of the transfer from abroad.

Since the economy's growth rate will depend on $r$, it is important to know precisely how $r$ depends on $\theta_{T}$. Log-differentiating equation 11 with respect to $\theta_{T}$ yields

$$
\frac{d \ln r}{d \theta_{T}} \propto\left[\left(\frac{\alpha}{\theta_{T}}\right)-\left(\frac{1-\alpha}{1-\theta_{T}}\right)\right],
$$

with

$$
\frac{d \ln r}{d \theta_{T}}=0 \Leftrightarrow \theta_{T}=\alpha .
$$

In other words, the return to capital is maximized when the share of the capital stock that the economy allocates to tradables $\left(\theta_{T}\right)$ is exactly equal to 
the input share of tradables in final production $(\alpha)$. This rate of return, and ultimately the economy's growth rate, will be suboptimal when tradables receive a smaller share of capital. I next analyze the circumstances under which such inefficiencies obtain.

\section{Sectoral Allocation of Capital}

The allocation of capital between the tradable and the nontradable sectors will depend both on the relative demand for the two goods and on the relative profitability of producing them. Consider the latter first. In equilibrium, capital will be allocated such that its (private) value marginal product is equalized in the two sectors. As discussed previously, I presume that each sector faces an "appropriability" problem, arising from either institutional weaknesses or market failures or both. I model this by assuming that private producers can retain only a share $1-\tau_{i}$ of the value of producing each good $i=T, N$. In other words, $\tau_{T}$ and $\tau_{N}$ are the effective "tax" rates faced by producers in their sector. Let the relative price of tradables $p_{T} / p_{N}$ be denoted by $R$. This is my index of the "real exchange rate." The equality between the value marginal product of capital in the two sectors can then be expressed as

$$
\left(1-\tau_{T}\right) R \varphi A_{T}\left(\theta_{T} \bar{k}\right)^{\varphi-1}=\left(1-\tau_{N}\right) \varphi A_{N}\left[\left(1-\theta_{T}\right) \bar{k}\right]^{\varphi-1},
$$

which simplifies to

$$
\left(\frac{\theta_{T}}{1-\theta_{T}}\right)^{\varphi-1}=\left(\frac{1-\tau_{N}}{1-\tau_{T}}\right) \frac{1}{R} \frac{A_{N}}{A_{T}} .
$$

This is a supply-side relationship which says that the share of capital allocated to tradables increases with the relative profitability of the tradable sector. This relative profitability in turn increases with $R$, $\tau_{N}$, and $A_{T}$ and decreases with $\tau_{T}$ and $A_{N}$ (remember that $\varphi-1<0$ ). The SS schedule is positively sloped between $\theta_{T}$ and $R$, as is shown in figure 7 .

Now turn to the demand side. In view of the Cobb-Douglas form of the production function for the final good, the demands for the two intermediate goods are given by

$$
\begin{gathered}
\alpha y=p_{T} y_{T}=p_{T}\left(\frac{1}{1-\gamma}\right) q_{T}=p_{T}\left(\frac{1}{1-\gamma}\right) A_{T}\left(\theta_{T} \bar{k}\right)^{\varphi} \\
(1-\alpha) y=p_{N} y_{N}=p_{N} q_{N}=p_{N} A_{N}\left[\left(1-\theta_{T}\right) \bar{k}\right]^{\varphi} .
\end{gathered}
$$

Taking the ratios of these two expressions and rearranging terms, 
Figure 7. Allocation of Capital and the Real Exchange Rate in Equilibrium

Real exchange rate $R$

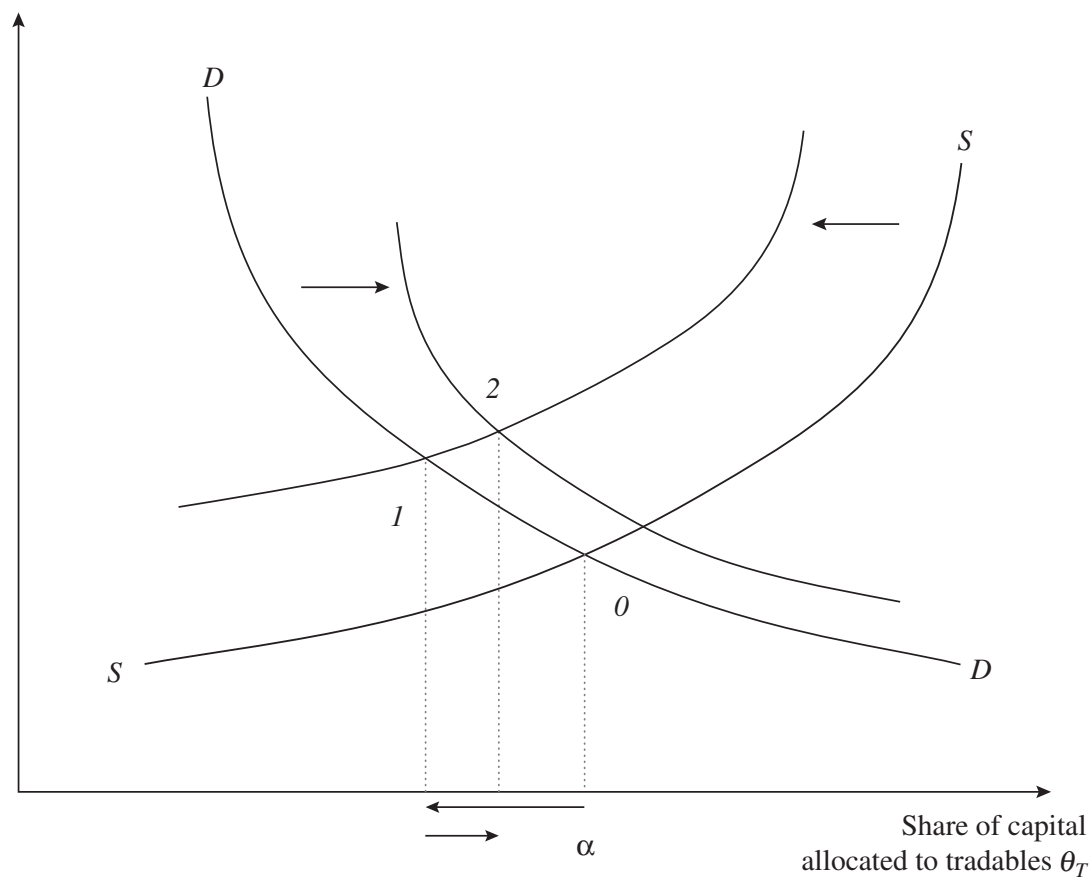

Source: Author's model described in the text.

$$
\left(\frac{\theta_{T}}{1-\theta_{T}}\right)^{\varphi}=(1-\gamma)\left(\frac{\alpha}{1-\alpha}\right) \frac{1}{R} \frac{A_{N}}{A_{T}} .
$$

This is a demand-side relationship between $\theta_{T}$ and $R$ and is shown as the DD schedule in figure 7 . This schedule is negatively sloped since an increase in $R$ makes tradables more expensive and reduces the demand for capital in that sector. Note that a reduction in $\gamma$ (a smaller inward transfer) shifts this schedule to the right: it increases $\theta_{T}$ at a given $R$ or increases $R$ at a given $\theta_{T}$.

\section{Equilibrium and Implications}

The equilibrium levels of $\theta_{T}$ and $R$ are given by the point of intersection of the SS and DD schedules. Several things should be noted about the nature of this equilibrium. To begin with, suppose that the economy is at an initial position where there is no transfer from abroad $(\gamma=0)$. If there 
are no appropriability problems in either of the intermediate-goods sectors, such that $\tau_{T}=\tau_{N}=0$, then it is relatively easy to confirm that the equilibrium is one where $\theta_{T}=\alpha$ (point 0 in figure 7). This ensures that the returns to capital and growth are maximized. Now suppose that $\tau_{T}$ and $\tau_{N}$ are positive but that their magnitude is identical $\left(\tau_{T}=\tau_{N}>0\right)$. One can see from equation 11 that the equilibrium remains unaffected. As long as the distortion affects tradables and nontradables equally, $\theta_{T}$ remains at its growthmaximizing level.

Things are different when $\tau_{T} \neq \tau_{N}$. Suppose that $\tau_{T}>\tau_{N}$, which I have argued is the more likely situation. Relative to the previous equilibrium, this entails a leftward shift in the SS schedule. In the new equilibrium (point 1 in figure 7), $\theta_{T}$ is lower (and $R$ is higher). Because $\theta_{T}<\alpha$, the economy pays a growth penalty as a result of the tradable sector being too small. Note that the endogenous real depreciation plays a compensatory role, but only a partial one.

Starting from this new equilibrium (where $\tau_{T}>\tau_{N}$ and $\theta_{T}<\alpha$ ), it is entirely possible that a negative transfer would improve the economy's growth. That is because a reduction in $\gamma$ leads to an increase in the equilibrium level of the real exchange rate and moves $\theta_{T}$ closer to $\alpha$. In terms of figure 7, a fall in $\gamma$ shifts the DD schedule to the right and causes both $R$ and $\theta_{T}$ to rise (point 2). Whether growth also increases ultimately remains uncertain, because the reduction in $\gamma$ also has a direct negative effect on growth (see equation 11). But if $\sigma$ is sufficiently high, one can always generate cases where this is on balance growth promoting. In such cases, the real depreciation generated by the negative external transfer becomes a second-best instrument to offset the growth costs of the differential distortion of tradables.

\section{Policy Implications}

The main point of this paper can be stated succinctly. Tradable economic activities are "special" in developing countries. These activities suffer disproportionately from the institutional and market failures that keep countries poor. A sustained real depreciation increases the relative profitability of investing in tradables and acts in second-best fashion to alleviate the economic cost of these distortions. It speeds up structural change in the direction that promotes growth. That is why episodes of undervaluation are strongly associated with more rapid economic growth.

Are my quantitative estimates of the growth effects of undervaluation plausible? For developing countries my estimates of $\hat{\delta}$ range from 0.063 
(albeit in a highly reduced sample, in column 4-2 of table 4) to 0.012 (in the last column of table 3 ) and cluster around 0.020 . If one takes the last number as a central estimate, the implication is that an undervaluation of, say, 20 percent boosts annual growth by 0.4 percentage point. Can the channel I have focused on deliver effects of this magnitude? Remember that the mechanism that generates growth here is structural change. So the answer obviously depends on the size of the gaps between social marginal products in tradable (especially industrial) and nontradable sectors. I have already given some reasons for why these gaps can be quite large. A long tradition of thought on economic dualism in developing countries takes the persistence of large differences between marginal products in the advanced, "formal" parts of the economy (such as industry) and marginal products elsewhere as the very essence of underdevelopment. Detailed industry studies carried out recently by the McKinsey Global Institute provide some striking, if indirect, evidence on the magnitude of these gaps. ${ }^{37}$ They find that productivity levels in the most advanced firms and sectors of developing economies are not too distant from the frontier in the rich economies. Since average productivity in these developing economies is a fraction of that prevailing in the rich economies, the implied intersectoral differences within developing economies are quite large. This paper's distinction between tradable and nontradable sectors maps directly onto this dualistic structure, since most (nonagricultural) tradable activities in a typical developing country are formal whereas most nontradable activities (except for public services) are informal..$^{38}$

There is an obvious parallel between the argument I have developed here and the results presented in a recent paper by Eswar Prasad, Raghuram Rajan, and Arvind Subramanian, ${ }^{39}$ who note that fast-growing developing countries have tended to run current account surpluses rather than deficits.

37. See, for example, McKinsey Global Institute (2001, 2003).

38. A simple finger exercise can be helpful here. Denote the productivity premium in industry by $\psi$ and the share of employment in industry by $\lambda_{I}$. Some straightforward algebra can establish that the growth effect of reallocating labor to industry in the amount $d \lambda_{I}$ is given by growth impact $=\left[\psi /\left(1+\psi \lambda_{I}\right)\right] d \lambda_{I}$. A reasonable assumption on the industrial premium (at the margin) would be that $\psi=50$ percent, and a typical industrial share of labor is $\lambda_{I}=0.20$. Note from the second column of table 7 that a 20 percent undervaluation would be associated with an increase of 0.84 percentage point in industry's share of total employment $\left(d \lambda_{I}=0.042 \times 0.2=0.0084\right)$. Applying the formula, an increase in the industrial labor share of 0.84 percentage point would be expected to generate additional growth equal to 0.38 percentage point, which is virtually identical to the result obtained using the coefficient estimates from the growth regressions ( 0.4 percentage point).

39. Prasad, Rajan, and Subramanian (2007). 
This runs counter to the view that developing countries are constrained by external finance, and to the presumption that capital inflows supplement domestic saving and enable more rapid growth. ${ }^{40}$ One of the explanations that Prasad and his coauthors advance is that capital inflows cause a real appreciation and hurt growth through reduced investment incentives in manufactures. They also provide some evidence on this particular channel. Even though these authors focus on the costs of overvaluation rather than the benefits of undervaluation, their concern with the real exchange rate renders their paper complementary to this one.

A maintained hypothesis in this paper thus far has been that the real exchange rate is a policy variable. Strictly speaking, this is not true, as the real exchange rate is a relative price and is determined in general equilibrium along with all other relative prices. But governments have a variety of instruments at their disposal to influence the real exchange rate, and the evidence is that they use them. Maintaining a real undervaluation requires either higher saving relative to investment or lower expenditure relative to income. This can be achieved through fiscal policy (a large structural surplus), incomes policy (redistribution of income to high savers through real wage compression), saving policy (compulsory saving schemes and pension reform), capital account management (taxation of capital account inflows, liberalization of capital outflows), or currency intervention (building up foreign exchange reserves). Experience in East Asia as well as elsewhere (for example, Tunisia) shows that countries that target the real exchange rate (that is, follow a policy of "competitiveness") can have a fair amount of success.

Table 10 presents some systematic evidence on how policy choices feed into the real exchange rate and undervaluation. The table shows the results of regressing UNDERVAL on a series of independent variables in a panel with fixed effects. The baseline specification (column 10-1) includes the following regressors: the terms of trade, government consumption (as a percent of GDP), an index of capital account liberalization (KAOPEN), and a set of dummy variables capturing the exchange rate regime in force. KAOPEN comes from Menzie Chinn and Hiro Ito and is a continuous variable designed to capture the extent and intensity of capital controls. ${ }^{41}$ It increases as a country's capital account regime becomes more liberal. The exchange rate regime indicators come from Ethan Ilzetzki, Carmen Reinhart, and Kenneth Rogoff and are entered as separate dummy vari-

40. Rodrik and Subramanian (forthcoming).

41. Chinn and Ito (2006). 
Table 10. Panel Regressions of Undervaluation on Selected Policy and Other Variables $^{\mathrm{a}}$

\begin{tabular}{|c|c|c|c|c|}
\hline \multirow[b]{2}{*}{ Independent variable } & \multicolumn{4}{|c|}{ Regression } \\
\hline & $10-1$ & $10-2$ & $10-3$ & $10-4$ \\
\hline ln terms of trade & $\begin{array}{l}-0.139 * * * \\
(-3.52)\end{array}$ & $\begin{array}{l}-0.164 * * * \\
(-4.14)\end{array}$ & $\begin{array}{l}-0.167 * * * \\
(-4.09)\end{array}$ & $\begin{array}{l}-0.115^{* * *} \\
(-2.86)\end{array}$ \\
\hline $\begin{array}{l}\text { Government consumption } \\
\text { as share of GDP }\end{array}$ & $\begin{array}{l}-0.793 * * * \\
(-4.35)\end{array}$ & $\begin{array}{l}-0.680 * * * \\
(-3.53)\end{array}$ & $\begin{array}{l}-0.519 * * * \\
(-2.61)\end{array}$ & $\begin{array}{l}-0.045 \\
(-0.23)\end{array}$ \\
\hline $\begin{array}{l}\text { Capital account openness } \\
\qquad(K A O P E N)^{\mathrm{b}}\end{array}$ & $\begin{array}{l}-0.031 * * * \\
(-5.70)\end{array}$ & $\begin{array}{l}-0.029 * * * \\
(-5.39)\end{array}$ & $\begin{array}{l}-0.026 * * * \\
(-4.56)\end{array}$ & $\begin{array}{l}-0.031 * * * \\
(-5.98)\end{array}$ \\
\hline \multicolumn{5}{|l|}{ Exchange rate regime dummies: ${ }^{\mathrm{c}}$} \\
\hline Crawl or managed float & $\begin{array}{l}0.068 * * * \\
(4.86)\end{array}$ & $\begin{array}{l}0.065^{* * * *} \\
(4.64)\end{array}$ & $\begin{array}{l}0.065^{* * * *} \\
(4.47)\end{array}$ & $\begin{array}{l}0.071 * * * \\
(4.87)\end{array}$ \\
\hline Float & $\begin{array}{r}0.027 \\
(0.85)\end{array}$ & $\begin{array}{l}0.028 \\
(0.89)\end{array}$ & $\begin{array}{l}0.058^{*} \\
(1.83)\end{array}$ & $\begin{array}{l}0.026 \\
(0.82)\end{array}$ \\
\hline Currency in free fall & $\begin{array}{l}0.161 * * * \\
(4.97)\end{array}$ & $\begin{array}{l}0.158 * * * \\
(4.86)\end{array}$ & $\begin{array}{l}0.172^{* * * *} \\
(5.21)\end{array}$ & $\begin{array}{l}0.162 * * * \\
(4.80)\end{array}$ \\
\hline $\begin{array}{l}\text { Dual market with missing } \\
\text { parallel market data }\end{array}$ & $\begin{array}{r}0.065 \\
(1.12)\end{array}$ & $\begin{array}{c}0.067 \\
(1.19)\end{array}$ & $\begin{array}{c}0.063 \\
(1.17)\end{array}$ & $\begin{array}{r}0.021 \\
(0.39)\end{array}$ \\
\hline $\begin{array}{l}\text { Gross domestic saving as } \\
\text { share of GDP }\end{array}$ & & $\begin{array}{l}0.310 * * * \\
(3.55)\end{array}$ & $\begin{array}{l}0.355^{* * *} \\
(3.80)\end{array}$ & $\begin{array}{l}0.492 * * * \\
(5.10)\end{array}$ \\
\hline FDI inflows as share of GDP & & & $\begin{array}{l}-0.376^{* * *} \\
(-3.11)\end{array}$ & $\begin{array}{l}-0.382^{* * * *} \\
(-3.04)\end{array}$ \\
\hline $\ln (1+$ inflation rate $)$ & & & & $\begin{array}{r}0.039 \\
(1.10)\end{array}$ \\
\hline No. of observations & 3,153 & 3,147 & 2,994 & 2,757 \\
\hline
\end{tabular}

Source: Author's regressions.

a. The dependent variable is $\ln$ UNDERVAL. All regressions include time and country fixed effects. See the text for definitions and sources of capital account openness and classifications of exchange rate regimes. Extreme observations are excluded as noted in table 1. Robust $t$ statistics are in parentheses. Asterisks indicate statistical significance at the $* 10$ percent, $* * 5$ percent, or $* * * 1$ percent level.

b. From Chinn and Ito (2006). Higher values indicate greater openness.

c. Classification of exchange rate regimes is from Ilzetzki, Reinhart, and Rogoff (2008). Countries with a rigid exchange rate regime are the excluded category.

ables identifying distinct regimes..$^{42}$ So, for example, the "Crawl or managed float" dummy takes the value of one when the country is classified as having a currency regime with a preannounced crawl, a de facto crawl, or a managed float and is zero otherwise. The excluded category is the set of observations with a rigid exchange rate (a fixed peg, a currency board, or a currency union). ${ }^{43}$ The remaining columns in the table augment the base-

42. Ilzetzki, Reinhart, and Rogoff (2008). The data for the indicators are available at www.economics.harvard.edu/faculty/rogoff/files/ERA_Background_Material.htm.

43. "Crawl or managed float" corresponds to categories 2 and 3 in Ilzetzki, Reinhart, and Rogoff"s (2008) "coarse" classification, and "rigid" corresponds to their category 1. 
line specification by adding domestic saving, inflation, and foreign direct investment (FDI) inflows as regressors. Among the variables considered, government consumption, capital account openness, the exchange rate regime, and inflation can be considered direct policy variables, whereas domestic saving and FDI inflows are indirectly affected by policy. The terms of trade are exogenous for most countries but are expected to have a determinate effect on the real exchange rate.

The results in table 10 are quite strong. As expected, positive terms of trade shocks are bad for undervaluation. More important for the present discussion, fiscal policies, capital account policies, and the choice of exchange rate regime all have quite significant effects on undervaluation. Increases in government consumption tend to produce a real appreciation, as do policies that liberalize the capital account. The coefficient on KAOPEN implies that going from the Chinese level of capital account restrictions in $2006($ KAOPEN $=-1.13)$ to the Mexican level $($ KAOPEN $=1.19)$ is associated with a decrease in UNDERVAL of around 7 percent. (Note that these effects are identified in these regressions from the variation within countries, not across countries, and are therefore more credible.) The operative channel, presumably, is that opening up the capital account invites inflows, which in turn cause the real appreciation.

The coefficients on the exchange rate regime dummies are also quite interesting The central finding here is that regimes in which the exchange rate is actively managed - crawling pegs or managed floats-produce larger undervaluations than do fixed-rate regimes, with a difference of around 7 percent. Unsurprisingly, periods in which the currency is in a "free fall" as defined by Ilzetzki, Reinhart, and Rogoff are also good for undervaluation. ${ }^{44}$ A pure float, by contrast, does not seem to generate significantly different levels of undervaluation.

The results in table 10 also show that high saving is good for undervaluation, whereas FDI inflows are bad. Both of these findings are in line with theoretical expectations. Finally, the level of inflation does not have a strong association with undervaluation, indicating that undervaluation need not come at the cost of inflation. In short, policy choices, particularly on the fiscal and external fronts, matter, and they do so in the manner suggested by straightforward economic logic.

44. Ilzetzki, Reinhart, and Rogoff (2008). It is worth noting that the growth effects of undervaluation, as detailed earlier in the paper, do not seem to depend on the type of exchange rate regime the country happens to have at the time. In particular, the results remain unchanged when the countries whose currencies are in a "free fall" are excluded from the sample. 
It is worth emphasizing once again that real exchange rate policy is only second-best in the context of the economic distortions discussed here. One of the side effects of maintaining a real overvaluation is a surplus on the current account (or a smaller deficit). This obviously has effects on other countries. Were all developing countries to follow this strategy, the developed countries would have to accept living with the corresponding deficits. This is a major issue of contention in U.S.-China economic relations at present. Moreover, when some developing countries (for example, the Asian economies) follow this strategy while others do not, the growth penalty incurred by the latter becomes larger as their tradable sector shrinks even further under the weight of Asian competition.

Conceptually, the first-best strategy is clear, if fraught with practical difficulties: eliminating the institutional and market failures in question would do away with the policy dilemmas. But recommending this strategy amounts to telling developing countries that the way to get rich is to get rich. A more practical approach is to subsidize tradables production directly, rather than indirectly through the real exchange rate. Real undervaluation is equivalent to a production subsidy plus a consumption tax on tradables. The direct strategy of subsidizing production of tradables achieves the first without the second. Hence it avoids the spillovers to other countries. A production subsidy on tradables boosts exports and imports simultaneously (provided the exchange rate, or wages, or both are allowed to adjust to equilibrate the current account balance) and therefore need not come with a trade surplus.

However, it goes without saying that production subsidies have their own problems. Fine-tuning them to address the perceived distortions would amount to a highly intricate form of industrial policy, with all the attendant informational and rent-seeking difficulties. Even if that were not a problem, the strategy would come into conflict with existing World Trade Organization rules that prohibit export subsidies. There is, it appears, no easy alternative to exchange rate policy.

ACKNOWLEDGMENTS I thank the Center for International Development for partial financial support, and David Mericle, Olga Rostapshova, and Andres Zahler for expert research assistance. I also thank Nathan Nunn for sharing his unpublished data with me. The paper has greatly benefited from the comments of Ricardo Hausmann, Arvind Subramanian, John Williamson, Michael Woodford, Peter Henry, and other Brookings panelists. 


\section{References}

Acemoglu, Daron, Simon Johnson, and James A. Robinson. 2001. "The Colonial Origins of Comparative Development: An Empirical Investigation." American Economic Review 91, no. 5 (December): 1369-1401.

Aguirre, Álvaro, and César Calderón. 2005. "Real Exchange Rate Misalignments and Economic Performance." Working Paper 315. Santiago: Central Bank of Chile, Economic Research Division (April).

Anderson, James E., and Douglas Mercouiller. 2002. "Insecurity and the Pattern of Trade: An Empirical Investigation." Review of Economics and Statistics 84, no. 2: 342-52.

Arellano, Manuel, and Stephen Bond. 1991. "Some Tests of Specification for Panel Data: Monte Carlo Evidence and an Application to Employment Equations." Review of Economic Studies 58, no. 2: 277-97.

Barro, Robert J., and Jong-Wha Lee. 2000. "International Data on Educational Attainment: Updates and Implications.” CID Working Paper 42. Center for International Development, Harvard University (April).

Berkowitz, Daniel, Johannes Moenius, and Katharina Pistor. 2006. "Trade, Law, and Product Complexity." Review of Economics and Statistics 88, no. 2: 363-73.

Bhalla, Surjit S. Forthcoming. "Second among Equals: The Middle Class Kingdoms of India and China." Washington: Peterson Institute for International Economics.

Blomberg, S. Brock, Jeffry Frieden, and Ernesto Stein. 2005. "Sustaining Fixed Rates: The Political Economy of Currency Pegs in Latin America." Journal of Applied Economics 8, no. 2 (November): 203-25.

Blundell, Richard, and Stephen Bond. 1998. "Initial Conditions and Moment Restrictions in Dynamic Panel Data Models." Journal of Econometrics 87, no. 1: 115-43.

Chinn, Menzie, and Hiro Ito. 2006. "What Matters for Financial Development? Capital Controls, Institutions, and Interactions." Journal of Development Economics 81, no. 1 (October): 163-92.

Dollar, David. 1992. "Outward-Oriented Developing Economies Really Do Grow More Rapidly: Evidence from 95 LDCs, 1976-1985.” Economic Development and Cultural Change 40, no. 3: 523-44.

Easterly, William. 2005. "National Policies and Economic Growth: A Reappraisal." In Handbook of Economic Growth, edited by Philippe Aghion and Steven Durlauf. Amsterdam: Elsevier.

Elbadawi, Ibrahim. 1994. "Estimating Long-Run Equilibrium Real Exchange Rates.” In Estimating Equilibrium Exchange Rates, edited by John Williamson. Washington: Institute for International Economics.

Fischer, Stanley. 1993. "The Role of Macroeconomic Factors in Growth.” Journal of Monetary Economics 32, no. 3: 485-512.

Freund, Caroline, and Martha Denisse Pierola. 2008. "Export Surges: The Power of a Competitive Currency." World Bank, Washington (October). 
Gala, Paulo. 2007. "Real Exchange Rate Levels and Economic Development: Theoretical Analysis and Econometric Evidence." Cambridge Journal of Economics 32, no. 2: 273-88.

Galvarriato, Aurora Gómez, and Jeffrey G. Williamson. 2008. "Was It Prices, Productivity or Policy? The Timing and Pace of Latin American Industrialization after 1870." NBER Working Paper 13990. Cambridge, Mass.: National Bureau of Economic Research (May).

Gluzmann, Pablo, Eduardo Levy-Yeyati, and Federico Sturzenegger. 2007. "Exchange Rate Undervaluation and Economic Growth: Díaz Alejandro (1965) Revisited.” Kennedy School of Government, Harvard University.

Hausmann, Ricardo. 2006. "Economic Growth: Shared Beliefs, Shared Disappointments?" Speech at the G-20 Seminar on Economic Growth in Pretoria, South Africa, August 2005. CID Working Paper 125. Center for International Development, Harvard University (June).

Hausmann, Ricardo, and Dani Rodrik. 2003. "Economic Development as SelfDiscovery." Journal of Development Economics 72, no. 2 (December): 603-33.

Hausmann, Ricardo, Jason Hwang, and Dani Rodrik. 2007. "What You Export Matters." Journal of Economic Growth 12, no. 1: 1-25.

Hausmann, Ricardo, Lant Pritchett, and Dani Rodrik. 2005. "Growth Accelerations." Journal of Economic Growth 10, no. 4: 303-29.

Heston, Alan, Robert Summers, and Bettina Aten. 2006. "Penn World Table Version 6.2." Center for International Comparisons of Production, Income and Prices at the University of Pennsylvania (September). pwt.econ.upenn.edu/ php_site/pwt_index.php.

Ilzetzki, Ethan O., Carmen M. Reinhart, and Kenneth Rogoff. 2008. "Exchange Rate Arrangements Entering the 21st Century: Which Anchor Will Hold?" University of Maryland and Harvard University.

Imbs, Jean, and Romain Wacziarg. 2003. "Stages of Diversification." American Economic Review 93, no. 1 (March): 63-86.

International Comparison Program. 2007. “2005 International Comparison Program Preliminary Results.” World Bank, Washington (December 17).

Johnson, Simon, Jonathan Ostry, and Arvind Subramanian. 2007. "The Prospects for Sustained Growth in Africa: Benchmarking the Constraints." IMF Working Paper 07/52. Washington: International Monetary Fund (March).

Kaufmann, Daniel, Aart Kraay, and Massimo Mastruzzi. 2008. "Governance Matters VII: Aggregate and Individual Governance Indicators, 1996-2007.” World Bank Policy Research Working Paper 4654. Washington: World Bank (June 24).

Levchenko, Andrei. 2004. "Institutional Quality and International Trade." IMF Working Paper 04/231. Washington: International Monetary Fund.

Levy-Yeyati, Eduardo, and Federico Sturzenegger. 2007. "Fear of Floating in Reverse: Exchange Rate Policy in the 2000s.” World Bank, Harvard University, and Universidad Torcuato di Tella.

McKinsey Global Institute. 2001. India: The Growth Imperative. San Francisco: McKinsey \& Co. 
2003. Turkey: Making the Productivity and Growth Breakthrough. Istanbul: McKinsey \& Co.

Méon, Pierre-Guillaume, and Khalid Sekkat. 2006. "Institutional Quality and Trade: Which Institutions? Which Trade?" Working Paper DULBEA 06-06.RS. Brussels: Université Libre de Bruxelles, Department of Applied Economics.

North, Douglass C. 1990. Institutions, Institutional Change and Economic Performance. Cambridge University Press.

Nunn, Nathan. 2007. "Relationship-Specificity, Incomplete Contracts and the Pattern of Trade." Quarterly Journal of Economics 122, no. 2 (May): 569-600.

Prasad, Eswar, Raghuram G. Rajan, and Arvind Subramanian. 2007. "Foreign Capital and Economic Growth.” BPEA, no. 1: 153-209.

Rajan, Raghuram G., and Arvind Subramanian. 2006. "Aid, Dutch Disease, and Manufacturing Growth." Peterson Institute for International Economics, Washington (August).

Ranjan, Priya, and Jae Young Lee. 2004. "Contract Enforcement and the Volume of International Trade in Different Types of Goods." University of California, Irvine.

Rauch, James E. 1999. "Networks versus Markets in International Trade.” Journal of International Economics 48, no. 1: 7-35.

Razin, Ofair, and Susan M. Collins. 1997. "Real Exchange Rate Misalignments and Growth." Georgetown University.

Rigobon, Roberto, and Dani Rodrik. 2005. "Rule of Law, Democracy, Openness and Income: Estimating the Interrelationships." Economics of Transition 13, no. 3 (July): 533-64.

Rodriguez, Francisco, and Dani Rodrik. 2001. "Trade Policy and Economic Growth: A Skeptic's Guide to the Cross-National Evidence." NBER Macroeconomics Annual 2000 15:261-325.

Rodrik, Dani. 1986. “'Disequilibrium' Exchange Rates as Industrialization Policy." Journal of Development Economics 23, no. 1 (September): 89-106.

. 2005. "Why We Learn Nothing from Regressing Economic Growth on Policies.” Kennedy School of Government, Harvard University (March). ksghome.harvard.edu/ drodrik/policy\%20regressions.pdf.

Rodrik, Dani, and Arvind Subramanian. Forthcoming. "Why Did Financial Globalization Disappoint?" International Monetary Fund Staff Papers.

Rodrik, Dani, Arvind Subramanian, and Francesco Trebbi. 2004. "Institutions Rule: The Primacy of Institutions over Geography and Integration in Economic Development." Journal of Economic Growth 9, no. 2 (June): 131-65.

Roodman, David. 2005. "xtabond2: Stata Module to Extend Xtabond Dynamic Panel Data Estimator." Center for Global Development, Washington. econ papers.repec.org/software/bocbocode/s435901.htm.

—. 2006. "How to Do xtabond2: An Introduction to 'Difference' and 'System’ Gmm in Stata.” Working Paper 103. Center for Global Development, Washington (December).

Sachs, Jeffrey, and Andrew Warner. 1995. "Economic Reform and the Process of Global Integration.” BPEA, no. 1: 1-95. 


\section{Comments and Discussion}

\section{COMMENT BY}

PETER BLAIR HENRY The real exchange rate is one of the most important prices in open-economy macroeconomics. In this paper Dani Rodrik provides a provocative analysis that links this key variable to the all-important issue of economic growth. In the process of doing so, the paper delivers at least two central messages. The first is empirical: real exchange rates exert a significant impact on economic growth, and developing countries that systematically undervalue their currencies in real terms grow faster than their counterparts that do not. The second message provides a theoretical explanation for the first: developing countries that systematically undervalue grow faster because undervaluation raises the rate of return to capital employed in the production of tradable goods by an amount sufficient to overcome the wide range of institutional problems that disproportionately affect that sector of the economy.

The paper contains a lot of fertile ground for a discussant: measurement issues, modeling assumptions, and implications of undervaluation for inflation and monetary policy, to name a few. My comment will focus primarily on the persuasiveness of the main results, their interpretation, and their policy implications.

Regarding the results, let me first offer a general statement about the paper's empirical contribution. In their article on exchange rate regimes and growth, Eduardo Levy Yeyati and Federico Sturzenegger demonstrate that developing countries with fixed nominal exchange rate regimes grow, on average, 0.7 percentage point per year more slowly than other countries. ${ }^{1}$ In theory, a fixed nominal exchange rate need not translate into a

1. Eduardo Levy Yeyati and Federico Sturzenegger, "To Float or to Fix: Evidence on the Impact of Exchange Rate Regimes on Growth," American Economic Review 93, no. 4 (2003): 1173-93. 
real overvaluation, but with rare exceptions that is the reality, so Rodrik's documentation that countries with overvalued currencies grow more slowly is not particularly novel.

What is new about the Rodrik paper is the demonstration that countries with undervalued currencies systematically grow faster. A 50 percent undervaluation is associated with a five-year growth rate that is about 1.3 percentage points above the country-specific mean.

The paper tries hard to disentangle causation from correlation. Building on his previous work with Ricardo Hausmann and Lant Pritchett, ${ }^{2}$ Rodrik examines the relationship between growth accelerations and undervaluation, asking the following question: Conditional on experiencing a growth acceleration, have countries done so with the help of an undervalued currency? In general, I applaud the use of an episodic approach to the data, but the problem with the question being asked is that it selects episodes on the basis of the desired outcome. Cutting the data in this way throws out important information about the number of times that large real depreciations occurred without any growth acceleration following in due course.

Instead of picking growth acceleration episodes and examining undervaluation relative to the beginning of those episodes, why not turn the analysis on its head? Using an appropriate definition, one could identify episodes of large sustained real depreciations and examine the time path of economic growth and the allocation of real resources after the onset of the depreciation. If the real exchange rate does indeed exert a causal effect, one should observe faster growth and a shift of resources from the nontradable to the tradable sector.

Cutting the data on episodes of large real depreciations would also focus attention on the important issue of levels versus changes. It is one thing to say that countries grow faster when the real exchange rate is at an undervalued level. But such a statement reveals nothing about the optimal way to change the real exchange rate to reach a level at which robust growth can occur. It would be useful to know if the way in which a country's currency becomes undervalued seems to matter for subsequent growth outcomes.

For instance, the words "nominal devaluation" do not appear anywhere in the paper. Yet a large nominal devaluation is one of the quickest ways of achieving a real depreciation. In fact, Ilan Goldfajn and Rodrigo Valdes have shown that most countries exit episodes of overvaluation not through

2. Ricardo Hausmann, Lant Pritchett, and Dani Rodrik, "Growth Accelerations," Journal of Economic Growth 10, no. 4 (2005): 303-29. 
adjustments in the price level, but through large nominal devaluations of the currency. ${ }^{3}$ Of course, wage and price compression can do the job without a devaluation. Disinflation reduces the domestic price level relative to the international price level, but this process can take a long time and exact a heavy cost in terms of lost output and higher unemployment.

The issue of how to change the real exchange rate raises the question of why undervaluation produces faster growth in the first place. One's natural inclination is to think that a competitive real exchange rate generates growth through an improvement in the trade balance. But Rodrik argues that the statistical relationship he uncovers between undervaluation and growth is not simply a story of export-led growth. To explain why undervaluation has an impact on growth, he therefore introduces an intermediate goods version of the dependent economy model. The logic of the model is straightforward. Absent any frictions, the real exchange rate settles at a level that equalizes the marginal return of resource allocation in the tradable and the nontradable sectors, thereby maximizing their contribution to growth. Associated with this optimality condition are the fractions of resources that get devoted to the production of tradable and nontradable goods.

The story changes in the presence of distortions, and the paper introduces two of them: a tax that reduces producers' rate of return to capital in the tradable sector, and another tax that reduces the return to capital in nontradables. We are told to think of these taxes as proxies for poor institutions. When the institutional tax on tradable and nontradable returns is the same, no real consequences ensue, as the fraction of resources devoted to the tradable sector remains at its growth-maximizing level. The key to the model, then, is that the institutional tax on returns in each sector not be the same. For Rodrik's story to work, one has to believe that poor institutions are much more costly for the producers of traded goods.

It is not clear that this is true across the board. Although it is easy to believe that a poor contracting environment hurts manufacturers more than barbers, the comparison between manufacturing and construction, for example, is less obvious. A major builder relies on many of the same factors as a manufacturer: suppliers, subcontractors, customers, and financial and legal support. Even if one accepts Rodrik's story that poor institutions have a disproportionately large negative effect on tradable goods, the analysis comes up flat, because the paper does not provide a way of

3. Ilan Goldfajn and Rodrigo Valdes, "The Aftermath of Appreciations," Quarterly Journal of Economics 114, no. 1 (1999): 229-62. 
quantifying just how important (or trivial) the distortion is for production over all.

Without a means of quantifying the negative impact of distortions in the contracting environment (or the positive impact of undervaluation), it is not clear what policy conclusions to draw from the paper's results. More generally, although Rodrik demonstrates that temporarily faster growth is one benefit of undervaluation, the paper does not provide a welfare analysis. This is important, because undervaluation has costs as well as benefits. To draw reliable policy conclusions, one needs to know more about the costs of undervaluation and how they compare with the benefits of faster growth. There are at least two potential costs of real undervaluation.

First, undervaluation subsidizes producers in the tradable goods sector at the expense of consumers. In the context of this model, which, as mentioned, never really discusses the nominal exchange rate, one can think of undervaluation as roughly equivalent to a policy of forced saving. Therefore, the critical question is whether one can conclude that faster growth in this context is welfare enhancing. In other words, given the population's rate of time preference, are people made better off by consuming less today than they would otherwise choose? The answer is far from clear, and I would add that this is more than a theoretical consideration. If one is considering the impact on growth of a policy change such as trade liberalization or the removal of capital controls, it is possible to write down models in which strange, counterintuitive things happen and aggregate welfare falls. But one has to try very hard to do that, because when one moves from a scenario in which people have fewer choices (closed markets) to one where they have more choices (open markets), people are usually made better off. Introducing distortions, on the other hand, generally reduces utility. In this case the distortion is that real undervaluation interferes with the price signal that drives the relative production and consumption of tradable and nontradable goods. Although it is true that the distortion occurs in a second-best world, I do not think one can conclude that welfare improves. Again, to make that case, one needs to know just how great the benefits of undervaluation are relative to the costs it imposes.

A second, well-known cost of a real undervaluation is that it generates destabilizing pressure on the balance of payments and attendant inflationary pressure. Suppose that Mexico chooses to undervalue the peso vis-à-vis the dollar. With Mexico's nominal exchange rate, in terms of pesos per dollar, set higher than the market clearing rate, Mexico will run a chronic surplus in tradable goods. Those surpluses will generate a 
commensurately large inflow of dollars to the central bank. Since the exchange rate is not allowed to adjust, the quantity of currency in circulation will rise in concert with the excess demand for Mexican tradables. If there is no adjustment in the exchange rate, over time the imbalance gets reflected in rising reserves and inflation, unless the central bank is able to successfully sterilize the inflow.

Some of Rodrik's other research actually highlights the potentially large welfare cost associated with accumulating excess foreign reserves. ${ }^{4}$ Since a policy of undervaluation is isomorphic to a policy of excess reserve accumulation, I am surprised that the paper does not try to reconcile the apparent inconsistency between the arguments in favor of undervaluation in this paper with Rodrik's earlier stance that emerging economies are overaccumulating reserves.

It is also worth emphasizing that although small, open economies may safely ignore the worldwide externalities of their policy choices, the same cannot be said for large countries. For example, if Barbados were to choose a policy of grossly undervaluing its currency, it could safely assume that its policy choice would have a negligible impact on the world balance of trade. The same assumption would be invalid for a large country. Furthermore, policies that are benign when implemented by a single country may be harmful if pursued by many countries simultaneously. From an individual country's point of view, a policy of undervaluation promotes export growth. But we all know very well the terrible externalities associated with a world in which everyone tries to undervalue at once. Whether this is done through a cascading series of competitive devaluations or through tighter fiscal policy, the consequences are largely the same. Rodrik likes to argue that countries need policy space. Such space is often appropriate and beneficial, but negative externalities of the type just mentioned are precisely the reason we have international organizations that try to encourage mutually beneficial exchange rate policies.

Turning from costs back to benefits, one implication of the model is that an outward transfer depreciates the currency. This real depreciation raises the rate of return to capital in the nontradable sector, improves resource allocation, and therefore acts as a second-best strategy for alleviating the implicit tax associated with poor institutions. Rodrik justifies this policy prescription on the grounds that foreign capital inflows do not contribute to growth. The support for such a claim comes, in part, from the paper by

4. Dani Rodrik, "The Social Cost of Foreign Exchange Reserves," International Economic Journal 20, no. 3 (2006): 253-66. 
Eswar Prasad, Raghuram Rajan, and Arvind Subramanian that I discussed in these pages about eighteen months ago. ${ }^{5}$ There I outlined several reasons why the data did not support the authors' claims about the impact of foreign capital on growth.

I will not repeat that discussion today. But I will say that the assertion that capital inflows do nothing but fuel consumption booms does not stand up to scrutiny. An article I published in the December 2007 issue of the Journal of Economic Literature documents the mounting body of evidence that foreign resource flows into developing countries reduce their cost of capital, stimulate investment, and raise GDP per capita. ${ }^{6}$ Similarly, in a recent working paper, Diego Sasson and I document the large, positive impact of capital account liberalization on real wages and productivity. $^{7}$

None of this is to say that capital account liberalization is the secret to faster growth. In fact, I agree that the impact of capital inflows on the real exchange rate can be a major source of concern for small, open economies. Thailand's struggle with the real appreciation of the baht-roughly 20 percent against the dollar in 2006-07-provides an important case in point. Furthermore, I agree with the argument that Rodrik has made elsewhere, that emerging economies tend to rely too heavily on short-term debt. But if the problem is an overreliance on short-term debt, the real exchange rate is a rather indirect and blunt instrument for dealing with it. The principle of policy targeting suggests that it is much more efficient to address directly the imperfections in the international financial system that give market participants the incentive to accumulate large quantities of short-term debt that are privately optimal but carry large negative consequences for the general public.

Rodrik acknowledges that eliminating the institutional and market failures in question would be preferable to adopting policies that drive the real exchange rate away from its equilibrium value. He argues, however, that encouraging developing countries to improve their institutions amounts to telling them that the way to get rich is to get rich.

5. Eswar Prasad, Raghuram G. Rajan, and Arvind Subramanian, "Foreign Capital and Economic Growth." BPEA, no. 1 (2007): 153-209; Peter Blair Henry, "Comment [on Prasad, Rajan, and Subramanian]," BPEA, no. 1 (2007): 217-23.

6. Peter Blair Henry, "Capital Account Liberalization: Theory, Evidence and Speculation," Journal of Economic Literature 45, no. 4 (2007): 887-935.

7. Peter Blair Henry and Diego Sasson, "Capital Account Liberalization, Real Wages, and Productivity," Working Paper 13880 (Cambridge, Mass.: National Bureau of Economic Research, 2008). 
This line of argument feels paternalistic. A few years ago, economists engaged in much hand wringing over the problem of "original sin," with some claiming that elaborate financial engineering schemes were needed to help developing countries avoid the problem of accumulating dollardenominated debt. ${ }^{8}$ Developing countries, it was said, would need decades to achieve the level of institutional development necessary to enable them to issue debt denominated in their own currency. I argued that this view not only was far too pessimistic but implicitly assumed that developing countries are incapable of helping themselves. I also said that once developing country governments demonstrated a sustained commitment to sound policies, they would have no trouble issuing local currencydenominated debt. ${ }^{9}$

Time has been kind to my prediction. A recent report by the Bank for International Settlements (BIS) demonstrates just how much progress has been made on the development of local-currency bond markets..$^{10}$ According to the BIS, in 2000 the total stock of international emerging market bonds outstanding was $\$ 498$ billion; by 2005 that stock was $\$ 618$ billion. Subtracting the first number from the second gives a rough estimate of the cumulative amount of new international debt issued by emerging markets from 2000 to 2005: $\$ 120$ billion.

To gauge just how much the world has changed since 2000, consider the analogous figures for local-currency-denominated emerging market bonds. The BIS report tells us that at the end of 2000 the total stock of internationally issued emerging market bonds denominated in local currency was $\$ 20$ billion. By 2006 that stock had grown to $\$ 102$ billion, which implies that emerging markets issued $\$ 82$ billion in such bonds between 2000 and 2006. In other words, almost 70 percent ( $\$ 82$ billion divided by $\$ 120$ billion) of the internationally issued bonds of emerging market countries between 2000 and 2005 were denominated in local currency. This is a remarkable increase given that the market for such instruments was previously nonexistent.

A big reason behind the shift is the improved macroeconomic environment in emerging markets. In the words of the Committee on the Global

8. See, for example, Barry Eichengreen, "Financial Instability," in Global Crises, Global Solutions, edited by Bjørn Lomborg (Cambridge University Press, 2004).

9. Peter Blair Henry, "Perspective Paper on Financial Instability," in Global Crises, Global Solutions, edited by Bjørn Lomborg (Cambridge University Press, 2004).

10. Committee on the Global Financial System, "Financial Stability and Local Currency Bond Markets," CGFS Papers 28 (Basel: Bank for International Settlements, 2007). www.bis.org/publ/cgfs28.htm. 
Financial System, "With the support of better domestic macroeconomic policies, reliance on foreign currency debt has indeed been reduced in almost all emerging market economies.... Issuance of local currency bonds has expanded substantially and domestic bond markets have deepened." 11

Policies matter. There is no inherent conflict between persuading countries not to overvalue their currencies and encouraging them to enhance their institutional environments. Improving the material existence of millions of people around the world inevitably requires that governments do both.

\section{COMMENT BY}

MICHAEL WOODFORD In this paper Dani Rodrik offers a provocative argument for policies that seek to maintain an "undervalued" currency in order to promote economic growth. The key to his argument is the empirical evidence that he presents, indicating the correlation of his measure of undervaluation with economic growth in cross-country panel regressions.

Rodrik does not really discuss the measures that should be undertaken to maintain an undervalued currency or whether it is likely that a country that pursues undervaluation as a growth strategy should be able to maintain that undervaluation over time. For example, he remarks (as justification for interest in the question of a causal effect of undervaluation on growth) that "one of the key findings of the open-economy macroeconomic literature is that ... nominal exchange rates and real exchange rates move quite closely together." But although this is true, and although it is widely interpreted as indicating that monetary policy can affect real exchange rates (since it can obviously move nominal rates), it hardly follows that monetary policy alone can maintain a weak real exchange rate for long enough to serve as part of a long-run growth strategy.

Indeed, conventional theoretical models with short-run price stickiness that are perfectly consistent with the observed short-run effects of monetary policy on real exchange rates also imply that monetary policy should not have long-run effects. Rodrik also cites evidence showing that sterilized interventions in the foreign exchange market can affect real exchange rates. But economic theory suggests that interventions not associated with

11. Committee on the Global Financial System, p. 89. 
any change in current or subsequent monetary policy should have even more transitory effects. And the experiences of countries that have sought to use devaluation to boost economic growth have often found that the real exchange rate effect of a nominal devaluation is not long-lasting. The case of South Korea, discussed below, is an example.

Nonetheless, the point of Rodrik's paper is to provide evidence that undervaluation favors growth, on the assumption that policies to maintain undervaluation are available, and it is that central contention that I shall examine here. I find the evidence less persuasive than the paper suggests, for two reasons. First, I believe that the paper exaggerates the strength and robustness of the association between the real exchange rate and growth in the cross-country evidence. And second, even granting the existence of such a correlation, a causal effect of real exchange rates on growth is hardly the only possible interpretation.

HOW STRONG IS THE ASSOCIATION OF UNDERVALUATION WITH ECONOMIC GROWTH? Rodrik's key result is the panel regression reported in his table 1 , in which the coefficient in a regression of growth on his UNDERVAL measure is found to be significantly positive and substantial in magnitude. The relationship, he argues, is in fact confined to developing countries, as the coefficient is near zero when the sample is restricted to countries with GDP per capita greater than $\$ 6,000$ a year; for the sample consisting only of countries with incomes less than $\$ 6,000$ a year, the coefficient is both larger and has an even larger $t$ statistic.

However, it is quite possible that Rodrik's measure of undervaluation exaggerates this association. Apart from the constant and fixed-effect terms, his measure of undervaluation is equal to

$$
\ln U N D E R V A L_{i t}=\ln R E R_{i t}+0.24 \ln R G D P C H_{i t} .
$$

But since lagged income per capita is also included as a regressor in Rodrik's table 1 regressions, and since $t$ refers to a five-year period in these regressions, so that

$$
\text { growth }_{i t} \equiv(1 / 5)\left[\ln R G D P C H_{i t}-\ln R G D P C H_{i, t-1}\right],
$$

his specification is equivalent to a regression of the growth rate (for each country-date pair) on the variable $\ln R E R_{i t}+1.2$ growth $_{i t}$ and lagged income per capita, and $\hat{\delta}$ (the estimated coefficient on $\ln U N D E R V A L$ in his regression) would be the coefficient on the "growth-adjusted real exchange rate" in the alternative specification. This way of viewing Rodrik's regression specification makes it evident that a positive estimate of $\hat{\delta}$ need not 
indicate any association between real exchange rates and growth at allit may simply reflect the positive correlation between the growth rate and itself.

Rodrik defends the use of his constructed measure UNDERVAL on the ground that it is necessary to correct for the Balassa-Samuelson effect. One should expect a lower real exchange rate (more-expensive nontraded goods) for higher-income countries, owing to this effect; Rodrik then defines "undervaluation" as the degree to which a country's real exchange rate is higher than expected given the country's income per capita. The latter prediction is made by regressing $\ln R E R_{i t}$ on $\ln R G D P C H_{i t}$ in a panel regression with time effects but no country fixed effects, so that the correlation between countries' average real exchange rates and their average incomes can be used to estimate the relationship. The coefficient on income per capita in this first-stage regression is (the negative of) the 0.24 appearing in equation 1 above.

However, two objections must be raised to this argument. First, Rodrik's panel regressions in his table 1 already include country fixed effects. Hence, average differences in the level of the real exchange rate associated with particular countries (for example, the developing countries with low real exchange rates, for the reason explained by Balassa and Samuelson) would have no consequences for the regression coefficient $\hat{\delta}$, even in the absence of Rodrik's proposed "adjustment" of the real exchange rate measure. A further adjustment is needed only if the Balassa-Samuelson effect is expected to create a higher-frequency correlation between income and the real exchange rate as well-that is, if the fiveyear periods in which a country's income per capita is relatively higher are ones in which it should correspondingly have a relatively lower exchange rate. The fact that the Balassa-Samuelson effect is well established as a factor explaining long-run average differences between countries does not make it obvious that such a high-frequency effect should be important. (As a theoretical matter, this should be true only to the extent that it is also true at higher frequencies that variations in the rate of productivity growth in the production of tradables are an important source of variation in both aggregate output growth, on the one hand, and the relative price of tradables, on the other.)

Second, even supposing that the high-frequency Balassa-Samuelson effect exists, the proposed correction will not necessarily be the correct one and will generally introduce an upward bias in the estimated coefficient $\hat{\delta}$. The reason is that the Balassa-Samuelson effect is not a direct 
causal effect of income on the real exchange rate (or equivalently, on the relative price of tradables). Instead, it is a mechanism according to which both income and the relative price of tradables are affected by a third variable (the rate of productivity growth in the tradable sector), which creates a negative correlation between the two variables (to the extent that other factors do not also simultaneously affect both variables).

The correction proposed by Rodrik would be appropriate if one believed that income and the real exchange rate were determined by a structural model of the form

$$
\begin{gathered}
E=-\beta Y+P+u \\
Y=d E+v,
\end{gathered}
$$

where I now simply write $E$ for the log of the real exchange rate and $Y$ for the log of income per capita, $P$ is a policy variable (treated as exogenous), and $u$ and $v$ are additional exogenous disturbances. Here equation 2 is a structural model of real exchange rate determination, in which the term $-\beta Y$ represents the (high-frequency) "Balassa-Samuelson effect" for which Rodrik apparently wishes to correct, and the term $P$ indicates the kind of policy that can influence the degree of undervaluation, the effects of which upon growth Rodrik wishes to determine. Equation 3 is a structural model of income determination, in which the term $d E$ represents the growth effect of the real exchange rate as such (that is, independent of what has caused the exchange rate to vary) hypothesized by Rodrik. Although no such model is spelled out or defended, something of this form is implicit in Rodrik's empirical strategy.

Suppose that equations 2 and 3 are a correct model, and suppose further that one has a strategy that allows one to identify the correct value of $\beta$ (say, from the countries' long-run differences in incomes and in real exchange rates, on the supposition that there are no long-run cross-country differences in the terms $P$ or $u) .{ }^{1}$ Under these assumptions, the "adjusted" real exchange rate

$$
\tilde{E} \equiv E+\beta Y
$$

1. To simplify the discussion, I shall abstract from the problems created by the use of a generated regressor and treat the true value of $\beta$ as known with certainty. 
will provide a measure of the composite disturbance $\tilde{u} \equiv u+P$. Under the further simplifying assumption that $v$ is orthogonal to $\tilde{u}$, the coefficient $\hat{\delta}$ from a regression of $Y$ on $\tilde{E}$ will be a consistent estimator of

$$
\delta \equiv \frac{d}{1+\beta d}=\frac{\partial Y}{\partial P}
$$

This is precisely the interpretation that Rodrik wishes to give to his estimate of $\hat{\delta}$.

But among the several assumptions required for this approach to yield a consistent estimate of $\partial Y / \partial P$, note that the "Balassa-Samuelson effect" is treated as a direct effect of $Y$ on $E$ in equation 2. In fact, this is not the nature of the Balassa-Samuelson theory. Even if one considers the theory as referring to purely instantaneous and static effects (which therefore have the same quantitative form at all frequencies), the model should instead be one of the form

$$
\begin{aligned}
& E=-a T+P+u \\
& Y=c T+d E+v,
\end{aligned}
$$

where $T$ is a measure of productivity in the tradable sector and, according to the Balassa-Samuelson theory, the coefficients $a$ and $c$ are both positive. Here $P$ is again a policy that is hypothesized to directly affect the exchange rate, and $d E$ again indicates the hypothesized effect of exchange rate variations (from whatever source) on national income. I shall suppose that $T$ is an exogenous disturbance, independent of all of the factors $P, u$, and $v$.

Suppose now that the true structural model is of the form in equations 6 and 7 , but that one is able to correctly estimate the elasticity of the real exchange rate with respect to variations in income per capita due purely to variations in productivity of the tradable sector, which is what one needs for the Balassa-Samuelson adjustment proposed by Rodrik. That is, suppose that one has a correct estimate of the coefficient

$$
\beta \equiv-\frac{\partial E / \partial T}{\partial Y / \partial T}=\frac{a}{c-a d} .
$$

(This could be estimated by a cross-country regression of long-run average real exchange rates on long-run average levels of income per capita, under the assumption that there are no cross-country differences in the long-run average values of either $\tilde{u}$ or $v$.) And again suppose that one 
constructs an "adjusted" real exchange rate, defined as in equation 4. What will be the economic interpretation of the coefficient $\hat{\delta}$ obtained by regressing $Y$ on $\tilde{E}$ ? In particular, will it provide a consistent estimate of $\partial Y / \partial P$ ?

Under the assumption that $\beta$ is correctly estimated, $\tilde{E}$ will be a measure of "undervaluation" that has been purged of any effects of variations in the productivity of the tradable sector; specifically,

$$
\tilde{E}=\frac{c}{c-a d} \tilde{u}+\frac{a}{c-a d} v .
$$

In this sense one has controlled for variations in the real exchange rate due to the Balassa-Samuelson effect. But this does not suffice to make $\hat{\delta}$ a consistent estimate of $\partial Y / \partial P$. Even under the assumption (for simplicity) that $v$ is orthogonal to $\tilde{u}, \hat{\delta}$ is in this case a consistent estimate of

$$
\delta+\frac{1}{\beta^{2}} \frac{(a / c) \sigma_{v}^{2}}{(c / a)^{2} \sigma_{\tilde{u}}^{2}+\sigma_{v}^{2}},
$$

where $\delta$ is again defined as in equation 5 and $\sigma^{2}$ is the variance. But this quantity is not equal to

$$
\frac{\partial Y}{\partial P}=d
$$

for two distinct reasons. Even if $\sigma_{v}^{2}=0$, expression 8 will equal $\delta$ rather than $d$, but because the Balassa-Samuelson effect is not a direct effect of income on the exchange rate (as represented in equation 2), the policyrelevant elasticity is $d$ rather than $\delta$. But, likely more important, if $\sigma_{v}^{2}>0$, the second term in expression 8 represents an upward bias in $\hat{\delta}$. One would find a positive estimate for $\hat{\delta}$ even if the true policy elasticity $d$ were equal to zero.

Not only is the coefficient obtained from a regression on $\tilde{E}$ likely to be biased; it is far from obvious that this should be a more reliable estimate than would be obtained by simply regressing on the unadjusted real exchange rate. Assuming again that $v$ is orthogonal to $\tilde{u}$, my simple model implies that the coefficient $\hat{d}$ obtained by regressing $Y$ on $E$ should be a consistent estimator of the quantity

$$
\frac{d \sigma_{\tilde{u}}^{2}-\beta^{-1} a^{2} \sigma_{T}^{2}}{\sigma_{\tilde{u}}^{2}+a^{2} \sigma_{T}^{2}} .
$$


This will be an underestimate of the true policy elasticity $d$ (if $\beta>0$ and $\sigma_{\mathrm{T}}^{2}>0$ ), owing to the failure to correct for the Balassa-Samuelson effect. But the bias will be relatively small as long as

$$
a^{2} \sigma_{T}^{2}<<\sigma_{\tilde{u}}^{2},
$$

which is to say, as long as productivity growth in the tradable sector accounts for a relatively small share of total high-frequency variation in the exchange rate. This last assumption seems a fairly reasonable one, except over quite long periods.

How dependent are Rodrik's results on the use of the UNDERVAL measure? His table 3 presents results for corresponding panel regressions using a variety of simple real exchange rate measures instead of his "adjusted" measure. In most cases the measure of undervaluation is no longer a significant explanatory factor when the entire sample of countries is used. Rodrik instead stresses that when one restricts attention to the sample of developing countries, the coefficient on the measure of undervaluation remains significantly (at the 5 percent level or better) positive in three out of the four cases (albeit substantially smaller than when UNDERVAL is used).

These results indicate that within the sample of lower-income countries, there is a positive association between the level of the real exchange rate and growth, after one controls for country effects and time effects; Rodrik's basic finding is not purely an artifact of the way in which his preferred measure of undervaluation is constructed. Nonetheless, if one were to emphasize the results using the real exchange rate (as I would prefer), one would not only obtain a smaller estimated effect, but have more reason for concern for the robustness of the finding as well.

For example, when one uses the real exchange rate as the measure of undervaluation, it becomes more important to restrict attention to the sample of "developing" countries in order to find evidence of the association between undervaluation and growth. But this in turn leads to questions about what should define the sample of countries that are included. Table 1 illustrates the consequences for the value of the estimated coefficient $\hat{\delta}$ of alternative choices of the set of countries included in the sample. Here the measure of undervaluation used is the real exchange rate measure from the Penn World Tables (the one used in the first two columns of Rodrik's table 3). ${ }^{2}$ The first line of the table essentially replicates the result in

2. Note that among the real exchange rate measures that Rodrik considers in table 3 , this is the one that results in the most significant positive value for $\hat{\delta}$ when the sample is restricted to countries with income per capita less than $\$ 6,000$. 
Table 1. Estimates of the Coefficient on Rodrik's Undervaluation Measure for Different Samples

\begin{tabular}{lccc}
$\begin{array}{l}\text { Sample limited to countries } \\
\text { with income per capita }\end{array}$ & Coefficient & Standard error & t statistic \\
\hline Less than $\$ 6,000$ & 0.0144 & 0.0038 & 3.77 \\
Less than $\$ 8,000$ & 0.0091 & 0.0037 & 2.50 \\
Between $\$ 1,000$ and $\$ 8,000$ & 0.0077 & 0.0040 & 1.91
\end{tabular}

Source: Author's calculations.

Rodrik's table $3 .^{3}$ The second line shows, however, that the estimated coefficient is reduced by one-third if the income cutoff is raised from $\$ 6,000$ to $\$ 8,000 .{ }^{4}$ It is not obvious that only countries with income per capita less than $\$ 6,000$ should be regarded as developing countries; in particular, if the justification for expecting to observe the hypothesized relationship only in lower-income countries is that these countries have weaker institutions, it is not obvious that countries with incomes per capita between $\$ 6,000$ and $\$ 8,000$ do not also suffer from many of the institutional weaknesses that are common in the developing world. ${ }^{5}$ But the evidence for a positive association between the real exchange rate and growth is considerably weaker when these additional countries are included in the set of "developing" countries. Moreover, the evidence becomes weaker still if the lowest-income countries (those with income per capita less than $\$ 1,000)$ are excluded from the sample. (One is surely not much interested in using the experiences of these desperate countries as illustrations of a successful growth strategy.) When these countries are dropped from the sample (third line of table 1), the estimated effect is only about half as large as for the "developing" sample used by Rodrik and no longer significant at the 5 percent level.

DOES THE CORRELATION INDICATE CAUSALITY? Even granting the existence of a positive correlation between a country's real exchange rate and its growth rate, is it legitimate to interpret this as evidence of a causal effect of the exchange rate on growth? In particular, is it evidence of a causal mechanism that can be relied upon in predicting the effects of a policy of seeking to maintain a depreciated currency?

3. Rodrik reports a slightly larger coefficient (0.016) and a $t$ statistic of 3.74 .

4. As in Rodrik's regressions, the income level used in this classification is average real income per capita over the period 1950-2004, where real GDP per capita is taken from the Penn World Tables.

5. The countries in this set are Bulgaria, Chile, Kazakhstan, Mauritius, Poland, South Africa, South Korea, Swaziland, Taiwan, Turkmenistan, Uruguay, and Venezuela. 
I should begin by admitting that I suspect that at least some of the positive association found in the data does reflect episodes in which policies that manipulate the exchange rate have had significant consequences for growth - specifically, examples of a familiar sort, in which policies that maintain an overvalued currency create distortions that stifle economic activity. But Rodrik stresses that this well-known lesson is not the only connection between exchange rate policy and growth; the declared purpose of his paper is to establish that policies leading to undervaluation are beneficial to growth. Yet much of the evidence that he presents (and the only evidence using unadjusted measures of the real exchange rate) consists of correlations that might largely reflect cases of overvaluation. Beneficial effects of undervaluation on growth can hardly be established merely by observing that countries are able to reduce their growth rates by intervening to maintain an overvalued currency. For example, the policies used to maintain a severe overvaluation typically involve rationing of access to foreign exchange, and one may suppose that it is these controls, rather than the level of the exchange rate as such, that account for much of the reduction in economic performance; but if so, one can hardly argue on this ground that other types of interference with free convertibility will instead increase efficiency, as long as the controls keep the currency undervalued rather than overvalued. One might instead expect growth to be favored by a policy that does not create distortions of either sign.

Rodrik offers several comments on the issue of causality. The first is an assertion that although an inference of causality from real exchange rate depreciation to growth would be problematic "in a world where governments did not care about the real exchange rate and left it to be determined purely by market forces," in fact "most governments pursue a variety of policies with the explicit goal of affecting the real exchange rate." But there is a great leap between the observation that real exchange rates are affected by policy and an assumption that the real exchange rate is purely determined by policy, and by policies that are exogenous with respect to the state of the economy at that. Yet only under the assumption that the real exchange rate is an exogenous policy choice can one sidestep the issue of causality.

In fact, Rodrik admits that endogeneity of the real exchange rate is an issue, and he proposes two ways of dealing with it. One is an extension of his regression model to include additional explanatory variables, such as the inflation rate, government consumption as a share of GDP, and gross domestic saving as a share of GDP. Inclusion of additional variables lowers the coefficient $\hat{\delta}$ on the UNDERVAL variable, but the coeffi- 
cient remains significantly positive; ${ }^{6}$ this is taken to suggest that undervaluation does indeed have a positive effect on growth, even after one has controlled for possible sources of endogenous variation in the real exchange rate. In fact, Rodrik suggests that some of the endogenous variation in the exchange rate that has been controlled for ought really to be counted as policy-induced variation: "To the extent that [policies that reduce government consumption or increase saving] are designed to move the real exchange rate in the first place, they are part of what I have in mind when I talk of 'a policy of undervaluation." This last point, however, is hardly convincing: if it is shown that policies that increase saving, for example, increase economic growth even when policymakers adopt them because of their anticipated consequences for the real exchange rate, it would hardly follow that policymakers should therefore be advised to attempt to depreciate by whatever means possible, for the growth effect of the increased saving might occur through other channels than the effect on the real exchange rate. Moreover, the mere fact that one has controlled for some possible kinds of endogeneity of the real exchange rate is hardly a proof that the remaining variation is exogenous.

Rodrik's final argument is an assertion that "many of the plausible sources of bias ... would induce a negative relationship between undervaluation and growth, not the positive relationship I have documented." This, in his view, makes an interpretation of the positive value of $\hat{\delta}$ as reflecting omitted-variable bias implausible. Accordingly, it is perhaps worth discussing a simple example of how endogeneity of the real exchange rate could result in a positive correlation between the real exchange rate and growth, even under circumstances where devaluation would not stimulate economic activity at all.

I shall illustrate my point using a purposely oversimplified model of equilibrium real exchange rate determination. ${ }^{7}$ Consider a two-period $(t=$ $1,2)$ small, open economy model with two sectors $(j=T, N)$ producing tradables and nontradables, respectively. I assume a competitive world market for the $T$ good (which will also be the numeraire) and a world real

6. Of course, this robustness of the significantly positive coefficient may reflect the bias resulting from use of the UNDERVAL measure, discussed above.

7. In particular, my use here of a model in which monetary policy cannot affect the real exchange rate does not mean that I believe that, in reality, monetary policy cannot influence the real exchange rate, at least for a time. My point is simply to show that a positive empirical correlation between the real exchange rate and real activity need not imply anything about the magnitude of the growth effects of exchange rate policy, and that point is made most simply with a model in which there is no scope at all for monetary policy to affect real variables, even in the short run. 
interest rate $r>0$ (in terms of the $T$ good, between periods 1 and 2) that is unaffected by the net capital flows of the small country. Let the production technology in each sector $j$ and each period $t$ be of the Cobb-Douglas form,

$$
Y_{j t}=K_{j t}^{1-a_{j}} H_{j t}^{a_{j}},
$$

where $K_{j t}$ is the capital stock in sector $j, H_{j t}$ is hours of labor in that sector, and the coefficient $0<\alpha_{j}<1$ may be sector specific. The initial capital stocks $K_{j 1}$ of both sectors are given as parameters, and I assume that $K_{N 2}$, the capital stock of the $N$ sector in the second period, is given exogenously as well. (To simplify, I shall assume a constant exogenous value, $K_{N t}=K_{N}$, for both periods $t$.) The second-period capital stock of the tradable sector instead depends on investment spending $I$, according to the law of motion

$$
K_{T 2}=I+(1-\delta) K_{T 1},
$$

where $0<\delta<1$ is the rate of depreciation of capital in the $T$ sector.

I assume that the representative household in the small economy seeks to maximize

$$
U=U_{1}+\beta U_{2},
$$

where the contribution to utility $U$ in period $t$ is of the form

$$
U_{t}=\gamma \log C_{N_{t}}+(1-\gamma) \log C_{T_{t}}-\frac{\lambda}{1+v} H_{t}^{1+\nu},
$$

in which expression $C_{j t}$ is consumption in period $t$ of the sector $j \operatorname{good}, H_{t}$ is hours worked, and the preference parameters satisfy $\lambda, v>0$ and $0<\beta$, $\gamma<1$. For simplicity I assume competitive domestic spot markets each period for both labor and the $N$ good, neither of which is traded internationally. Finally, the government sets the nominal exchange rate each period, which then determines the domestic-currency price of the $T$ good in that period (by the law of one price). I shall suppose that the government also imposes a proportional tax $\tau$ on savings in period 1 , so that the real return received by domestic savers is $(1-\tau)(1+r)$. I abstract from government consumption; the government revenue raised by the tax is assumed to be simply rebated as a lump sum to households.

In any period $t$, given values for $\left(K_{T t}, Y_{T_{t}}\right)$, one can solve uniquely for equilibrium values of $H_{T}, H_{N t}, Y_{N t}=C_{N t}, C_{T t}, w_{t}$, and $P_{N t}$, where both the wage $w_{t}$ and the price of nontradables $P_{N t}$ are quoted in units of the $T$ good. (Thus, $w_{t}$ is a real wage and $P_{N t}$ is actually the relative price of nontrad- 
ables.) One can easily show that there is a unique, differentiable solution for each of these variables and that the solution functions satisfy (among other properties)

$$
\begin{gathered}
\frac{\partial C_{T}}{\partial Y_{T}}<0, \quad 0<\frac{\partial \log C_{T}}{\partial \log K_{t}}<-\frac{\partial \log C_{T}}{\partial \log Y_{T}}, \\
\frac{\partial Y_{N}}{\partial Y_{T}}<0, \quad 0<\frac{\partial \log Y_{N}}{\partial \log K_{T}}<-\frac{\partial \log Y_{N}}{\partial \log Y_{T}}, \\
\frac{\partial G D P}{\partial Y_{T}} \equiv 1+P_{N} \frac{\partial Y_{N}}{\partial Y_{T}}>0 \\
\frac{\partial P_{N}}{\partial Y_{T}}<0, \quad 0<\frac{\partial \log P_{N}}{\partial \log K_{T}}=-\frac{\partial \log Y_{N}}{\partial \log Y_{T}} .
\end{gathered}
$$

Using these solution functions, an intertemporal equilibrium can then be described as a set of values for the endogenous variables $\left(Y_{T 1}, K_{T 2}, Y_{T 2}\right)$ that satisfy the following three equilibrium conditions:

$$
\begin{gathered}
C_{T}\left(K_{T 1}, Y_{T 1}\right)+\left[K_{T 2}-(1-\delta) K_{T 1}\right]+\frac{C_{T}\left(K_{T 2}, Y_{T 2}\right)}{1+r}=Y_{T 1}+\frac{Y_{T 2}}{1+r} \\
C_{T}\left(K_{T 2}, Y_{T 2}\right)=\tilde{\beta}(1+r) C_{T}\left(Y_{T 1}\right) \\
\left(1-\alpha_{T}\right) Y_{T 2}=(1+r) K_{T 2},
\end{gathered}
$$

given values of the exogenous parameters $\left(K_{T 1}, r, \tilde{\beta}\right)$, where $\tilde{\beta} \equiv \beta(1-r)$.

Here equation 9 is the requirement that there be intertemporal balance in the country's capital account (assuming zero net foreign assets at the beginning of period 1); equation 10 is the Euler equation for an optimal saving decision by the representative household; and equation 11 is the first-order condition for profit-maximizing investment demand, stating that the anticipated marginal product of capital in period 2 must equal 1 plus the required real rate of return. ${ }^{8}$ One can again show that there is a unique solution to these three equations for the endogenous variables as differentiable functions of the exogenous parameters.

Consider now the consequences of an exogenous increase in the composite parameter $\tilde{\beta}$, which implies an increase in domestic households'

8. Note that since period 2 is the last period of the model, there is effectively 100 percent depreciation of capital in this period. 
willingness to save, as a result of either a change in preferences (an increase in $\beta$ ) or a change in policy that increases incentives for saving (a reduction in $\tau$ ). Total differentiation of the system of equations 9,10 , and 11 reveals that

$$
\frac{\partial Y_{T 1}}{\partial \tilde{\beta}}>0
$$

which implies in turn that

$$
\frac{\partial G D P_{1}}{\partial \tilde{\beta}}>0, \quad \frac{\partial P_{N 1}}{\partial \tilde{\beta}}<0, \quad \frac{\partial\left(Y_{T 1}-C_{T 1}\right)}{\partial \tilde{\beta}}>0 .
$$

Hence an increase in the willingness to save in period 1 (whether due to changing attitudes or to changing incentives) will simultaneously increase the production of tradables $\left(Y_{T 1}\right)$, the small country's exports $\left(Y_{T 1}-C_{T 1}\right)$, and its real GDP $\left(G D P_{1}\right)$, while reducing the relative price of nontradables $\left(P_{N 1}\right)$ and hence increasing the real exchange rate.

Note that this equilibrium scenario resembles the phenomenon often interpreted as "export-led growth": a real depreciation coincides with an increase in exports and an increase in total GDP (hence an increase in the growth rate). Moreover, if one were to compare a panel of small, open economies, to each of which the above model applies, with identical parameter values except for cross-country variation in the value of $\tilde{\beta}$, one would observe a positive correlation between a country's real exchange rate in period 1 and its growth rate in that period. ${ }^{9}$ Yet the high-growth countries would not be in this situation because of their exchange rate policies; their higher growth rates would be due to other factors (factors that favor a higher saving rate) that happen to lead both to a lower equilibrium real exchange rate and to higher GDP growth. Moreover, the model is one in which if a country were to use monetary policy to depreciate its currency in nominal terms, this would not affect growth (or any other real variables, including the real exchange rate); it would only raise the nominal domestic prices of both tradables and nontradables (without affecting their relative price).

It is true that there is a policy intervention, in the simple model, that would depreciate in real terms, namely, a reduction in the tax rate on sav-

9. The exogenous parameters taking identical values for the different countries are assumed to include GDP in the period immediately before period 1, with respect to which the period 1 growth rate is calculated. 
ings $\tau$, which is one of the factors determining the value of $\tilde{\beta}$. And such a policy change would increase GDP (through its effect on saving) in the same way that an increase in households' patience would. But it does not really make sense to call this a demonstration that a deliberate policy of exchange rate depreciation can be used to stimulate growth, since the most obvious example of a policy with that intent would be completely ineffective. $^{10}$

The example shows that it is certainly possible for an omitted variable to move both the real exchange rate and GDP in the same direction, so that this is a potential interpretation of a positive coefficient $\hat{\delta}$ in Rodrik's panel regression. But is this theoretical possibility likely to be of practical relevance? Here it is worth noting that the regressions reported in Rodrik's table 10 show that a country's ratio of gross domestic saving to GDP has a significant positive effect on his UNDERVAL measure; and of course, a higher saving rate is also correlated with higher growth, as many authors have noted, and as Rodrik's panel regressions in tables 4 and 5 show. (The latter regressions show that the saving rate is a significant variable in explaining differences in growth across country-time pairs, even when the undervaluation measure is also included in the regression, and that inclusion of the saving rate as an explanatory variable reduces the estimated coefficient on the undervaluation measure.)

Rodrik notes that the inclusion of the saving rate in the growth regressions does not completely eliminate the significance of UNDERVAL as an explanatory variable, and he concludes from this that endogeneity resulting from factors of the kind illustrated in the simple example do not fully account for the association between undervaluation and growth. But the fact that inclusion of a single proxy for factors of the kind represented by the simple example eliminates only part of the association between UNDERVAL and growth hardly establishes that endogenous mechanisms of this kind are not responsible for the correlation-in particular, for the cases in which undervaluation coincides with strong growth, as opposed to the cases in which overvaluation coincides with weak growth. ${ }^{11}$

10. Moreover, some other policies that would result in a real depreciation as a byproduct would lower rather than raise GDP growth.

11. Again, it is only the association of UNDERVAL with growth that is shown to be robust to inclusion of the saving rate in the regression, not the association between simple measures of the real exchange rate and growth. One should not expect the association between UNDERVAL and growth to be completely eliminated by the inclusion of any number of regressors representing determinants of the real exchange rate, because UNDERVAL also reflects the economy's growth rate, as explained above. 
The simple example also illustrates another important point. The mere existence of a positive correlation between the real exchange rate and growth (across some class of developing countries) need not be evidence of any greater distortions in the tradable sector that can in turn justify policies that essentially subsidize that sector. Ultimately, this is Rodrik's argument for the pursuit of undervaluation: one would like to subsidize the production of tradables, but for political economy reasons it may be most practical to do so by manipulating the exchange rate rather than through industrial policy. The main evidence Rodrik offers for the hypothesis of an inefficiently small relative size of the tradable sector in developing economies is the evidence for a stimulative effect of a real depreciation. Yet in the simple model, a positive correlation exists between the real exchange rate and growth - and faster growth is associated with a shift of resources from the nontradable to the tradable sector-but this does not mean that the equilibrium production of tradables is suboptimal. In the case that $\tau=0$, the intertemporal equilibrium maximizes the welfare of the representative household (subject to the constraint that trade with the rest of the world must satisfy intertemporal balance of the capital account), and the introduction of a subsidy for the production of tradables would reduce welfare, relative to that optimum. Similarly, the introduction of other sorts of market distortions that represent indirect ways of subsidizing the tradable sector would most likely reduce welfare, whether or not they would increase GDP.

A CASE STUDY: SOUTH KOREA. Ultimately, the issue of causality is unlikely to be settled using panel regressions of the kind that constitute Rodrik's main results, owing to a lack of suitable instruments for exogenous changes in exchange rate policy. Case studies can often be more illuminating in this regard. Here I consider only one, that of South Korea, which is one of the countries Rodrik cites to illustrate the association of growth with undervaluation (see his figure 1). One can obtain a more complete picture of the degree to which the Korean case supports Rodrik's thesis by looking at higher-frequency data (his figure 1 uses five-year averages) and at additional variables.

My figure 1 plots annual data for both the (official) nominal wondollar exchange rate and the implied real exchange rate, as well as Korean prices relative to U.S. prices. ${ }^{12}$ The figure shows the several large won devaluations of the 1950s and 1960s-in particular, those

12. The data are from the Penn World Tables and are the same data used by Rodrik in constructing the UNDERVAL measure that he plots. 
Figure 1. South Korea: Exchange Rates and Relative Prices, 1953-2004a

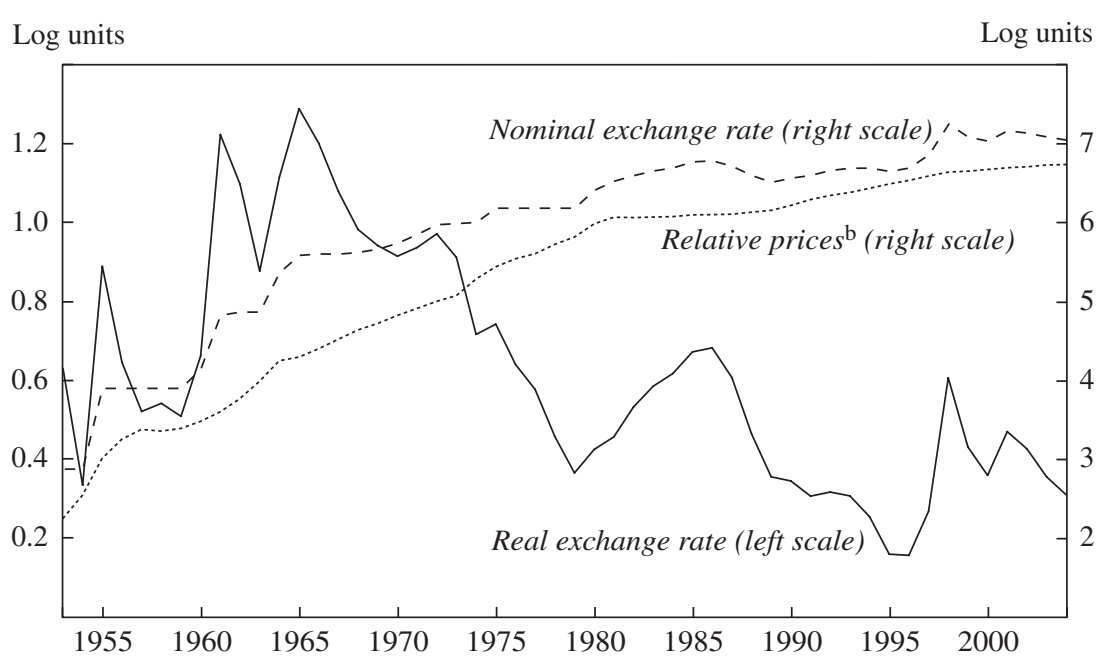

Source: Penn World Tables.

a. Exchange rates are against the dollar; a rise indicates a depreciation of the won.

b. Korean prices relative to U.S. prices.

of $1955,1960,1961$, and $1964 .{ }^{13}$ Each of these did result (at least temporarily) in a substantial real depreciation, providing clear evidence that at least some of the relatively high frequency variation in the real exchange rate in South Korea represents effects of exchange rate policy. But the figure also makes clear that devaluations need not have any long-lasting effect on the real exchange rate: much of the effect of the 1955 and 1961 devaluations had already been undone by increased inflation two years later. Indeed, this fact explains why the Korean government found additional large devaluations to be necessary so soon after the previous ones.

The 1964 devaluation might appear to have been more successful: for the next decade, Korea maintained a real exchange rate that was substantially weaker than it had been during most of the 1950s. Of course, this was also the decade over which Korea's real GDP growth accelerated to a rate of 6 to 8 percent a year (figure 2), which Rodrik interprets as supporting the view that an undervalued currency was the key to the Korean growth

13. A 30 percent devaluation in February 1960 was followed by another 100 percent devaluation in February 1961; the annual data are not of high enough frequency to show this as two distinct episodes. 
Figure 2. South Korea: Exchange Rates, Saving, and Economic Growth, 1953-2004

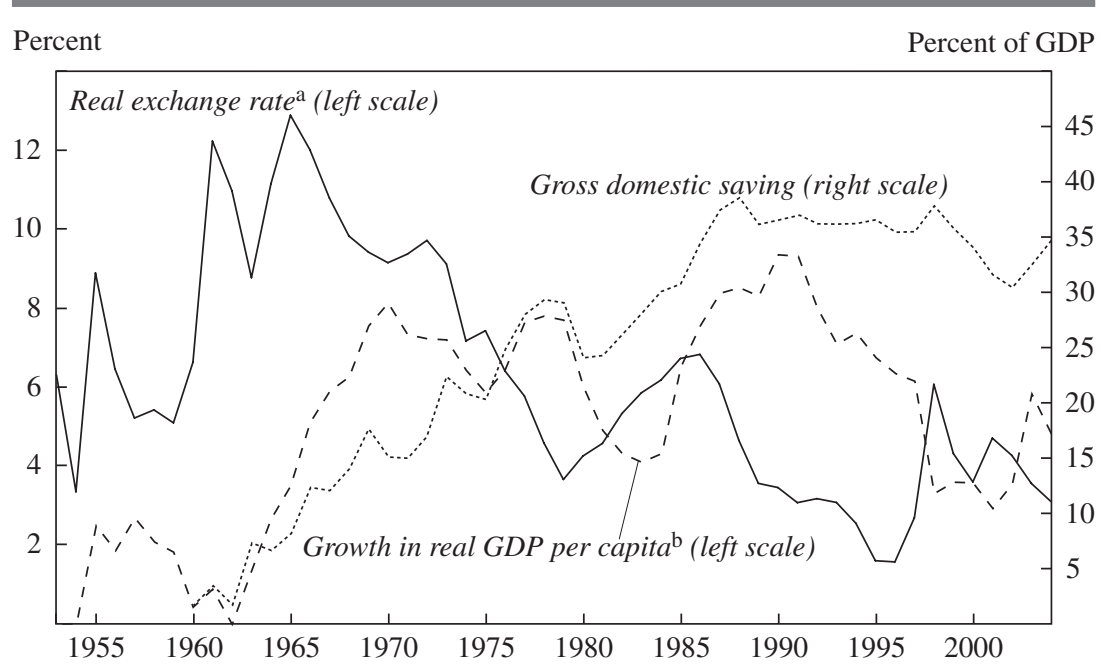

Source: Penn World Tables.

a. Logarithm of the real exchange rate from figure 1, divided by 10 .

b. Five-year moving average.

"miracle." But in order to attribute the sustained real depreciation to the 1964 devaluation, one must explain why earlier devaluations did not have similarly long-lasting effects.

An obvious interpretation would be as follows: the earlier devaluations were not associated with any change in the equilibrium real exchange rate, and therefore monetary policy could weaken the real exchange rate only temporarily; in contrast, the 1964 devaluation coincided with a weakening of the equilibrium real rate, so that the devaluation, rather than resulting in a true undervaluation, facilitated a shift in the real exchange rate that would have had to occur in any event. Why might the equilibrium real exchange rate have weakened? A clue is provided by the fact that gross domestic saving surged after the early 1960s, as figure 2 also shows.

Before 1965, ceilings on bank deposit rates in South Korea depressed household saving, since (under the high inflation of the time) the implied real interest rates on deposits were negative. Instead, households lent funds to the informal financial sector, where interest rates were quite high. By raising interest rate ceilings in 1965 and at the same time reducing inflation, the government brought household savings back into the banking system, and so reduced the cost of capital for businesses through more 
efficient intermediation. ${ }^{14}$ In addition, tighter fiscal policy increased public saving, further contributing to the sharp increase in overall domestic saving.

This increase in saving, which coincided fairly closely with the acceleration of economic growth, was likely an important cause of the growth miracle. Moreover, the simple model presented above shows that increased incentives for saving can also increase the equilibrium real exchange rate. This may be one of the reasons that Korea's equilibrium real exchange rate was higher in the late 1960s and early 1970s than earlier, so that the effects of the 1964 devaluation on the real exchange rate were not quickly reversed. Indeed, Kwang Suk Kim argues that Korea's persistent current account deficit and buildup of external debt in the decade after 1965 point to overvaluation, not undervaluation, of the won in this period (providing, incidentally, a further reason to doubt the accuracy of Rodrik's UNDERVAL measure). ${ }^{15}$

Of course, my interpretation of the Korean case does not imply that exchange rate policy is completely irrelevant to a country's development strategy. Overly tight regulation of financial flows can be an important impediment to growth, as seems to have been the case in Korea before the 1960 s, and policies that seek to maintain an overvalued currency will often require extensive controls. Hence the creation of conditions conducive to growth will mean, among other things, refraining from attempts to maintain a seriously overvalued currency. Moreover, the Korean case shows that the process of development may involve a reduction in the equilibrium real exchange rate (that is, that which would result from fully flexible wages and prices and an absence of impediments to capital flows). In such a case, a nominal devaluation can be valuable as a way of allowing the necessary real depreciation to occur without the more painful process of forcing wages and prices down in response to insufficient aggregate demand. But such a policy is not correctly described as the pursuit of an "undervalued" currency; rather, it is again an example of the wisdom of avoiding overvaluation, with the important proviso that the equilibrium exchange rate, with respect to which overvaluation must be defined, can easily change as the economic structure changes.

14. Kim, Kwang Suk, "The 1964-65 Exchange Rate Reform, Export-Promotion Measures, and Import-Liberalization Program." In Economic Development in the Republic of Korea: A Policy Perspective, edited by Lee-Jay Cho and Yoon Hyung Kim (Honolulu: EastWest Center, 1991, p. 137).

15. Kim, "The 1964-65 Exchange Rate Reform," p. 132. 
GENERAL DISCUSSION Lawrence Summers commented that if the findings of the paper are correct, the implications are striking: mercantilism is the right economic strategy for developing countries seeking faster growth. According to the paper, certain sectors of the economy are likely to generate externalities and contribute to growth in ways different from other sectors, and therefore policies that support those sectors are likely to be preferred. This argument is directly at odds with economists' traditional opposition to most forms of industrial policy. But Summers raised two problems that prevented him from being persuaded by the paper's results. First, he questioned whether the externalities in the tradable goods sector could be so large relative to those in the nontradable goods sector as to account for the estimated growth effect. Second, he doubted that all the benefits of such externalities would be realized within just five years, as the paper's empirical approach implied. Summers also criticized Rodrik's use of both time fixed effects and five-year measurement periods, on the grounds that they would likely obscure the longer-term impact. He argued that omitting the country fixed effects would allow a closer examination of permanent differences in the structure of national economies.

Richard Cooper broadly agreed with Rodrik's conclusion but observed that it was not a new idea: many of the Asian countries had adopted it in the second half of the twentieth century. Those countries followed a policy of currency undervaluation for two reasons: to promote reliable demand for their exports, and to encourage capital imports. Cooper disagreed with Summers that such a policy constituted mercantilism: mercantilism focuses on restricting imports, whereas this policy acts primarily on exports. On a more technical note, Cooper expressed reservations about the use of purchasing power parity-adjusted prices in determining overor undervaluation, given that those numbers are subject to significant revision.

Linda Goldberg commended the paper for attempting to grapple with the distortions limiting growth in developing countries, particularly those falling disproportionately on the industrial sector. However, she objected to the paper's exclusive focus on the real exchange rate as the mechanism for dealing with those distortions, since the real exchange rate is correlated with other policies and macroeconomic variables. She suggested looking instead at natural experiments directly related to industrial policy and focusing specifically on the sectors most affected by the distortions.

Pierre-Olivier Gourinchas cautioned against the use of the Penn World Tables as the main data source. Given the large changes in the most recent revision of the data, he suggested, as a robustness test, rerunning the 
paper's regressions using earlier versions of the Penn tables. Gourinchas also questioned the practice of defining the real exchange rate as the relative price of goods in the tradable and the nontradable sectors, since other literature has shown that movement in the real exchange rate is not driven by movements in these relative prices. He added that he would like to see more empirical evidence in support of the paper's main argument.

Kathryn Dominguez agreed with previous speakers about the role of undervaluation in overcoming distortions but added that maintaining a real undervaluation is a costly policy. She requested that Rodrik provide an explanation of how undervaluation should be achieved so that it is actually beneficial.

Frederic Mishkin discussed other possible mechanisms for encouraging growth, focusing primarily on improvements in institutions. A shift in output toward tradable goods creates incentives to improve institutions, particularly in the financial sector, to meet the need for additional capital. Such improvement leads to growth in other sectors as well, as previous literature has shown. 
